Review Article

\title{
Chlamydia trachomatis Infection in Pregnancy: The Global Challenge of Preventing Adverse Pregnancy and Infant Outcomes in Sub-Saharan Africa and Asia
}

\author{
Kristina Adachi, ${ }^{1}$ Karin Nielsen-Saines, ${ }^{1}$ and Jeffrey D. Klausner ${ }^{2,3}$ \\ ${ }^{1}$ Department of Pediatrics, David Geffen School of Medicine, UCLA, Los Angeles, CA 90024, USA \\ ${ }^{2}$ Department of Medicine, Division of Infectious Diseases: Global Health, David Geffen School of Medicine, \\ UCLA, Los Angeles, CA 90024, USA \\ ${ }^{3}$ Department of Epidemiology, Jonathan and Karin Fielding School of Public Health, UCLA, Los Angeles, CA 90024, USA \\ Correspondence should be addressed to Kristina Adachi; kadachi@mednet.ucla.edu
}

Received 23 October 2015; Accepted 9 February 2016

Academic Editor: Ma Luo

Copyright (C) 2016 Kristina Adachi et al. This is an open access article distributed under the Creative Commons Attribution License, which permits unrestricted use, distribution, and reproduction in any medium, provided the original work is properly cited.

Screening and treatment of sexually transmitted infections (STIs) in pregnancy represents an overlooked opportunity to improve the health outcomes of women and infants worldwide. Although Chlamydia trachomatis is the most common treatable bacterial STI, few countries have routine pregnancy screening and treatment programs. We reviewed the current literature surrounding Chlamydia trachomatis in pregnancy, particularly focusing on countries in sub-Saharan Africa and Asia. We discuss possible chlamydial adverse pregnancy and infant health outcomes (miscarriage, stillbirth, ectopic pregnancy, preterm birth, neonatal conjunctivitis, neonatal pneumonia, and other potential effects including HIV perinatal transmission) and review studies of chlamydial screening and treatment in pregnancy, while simultaneously highlighting research from resource-limited countries in sub-Saharan Africa and Asia.

\section{Introduction}

1.1. Chlamydia trachomatis in Pregnancy: A Global Problem. Over 2 decades following the landmark United Nations' (UN) International Conference on Population and Development in Cairo, which brought unprecedented attention to women's sexual and reproductive health, global statistics continue to reveal a high burden of maternal and infant morbidity and mortality [1,2]. In 2010, in an attempt to bridge some of these critical gaps, the UN launched the "Global Strategy for Women's and Children's Health" and the "Every Woman Every Child" movement [3]. With renewed commitment to improving the health of the world's most vulnerable women and children, the UN recently released its new "Global Strategy for Women's, Children's, and Adolescents' Health (20162030)" this past September 2015 [4].

STIs and pregnancy-related issues are among these historically neglected health problems and continue to be important sources of healthy life years lost for women $[1,5,6]$.
In Africa, it is estimated that 92.6 million new cases of the curable STIs (Chlamydia trachomatis, Neisseria gonorrhoeae, Treponema pallidum, and Trichomonas vaginalis) occur, whereas 78.5 million and 128.2 million new cases are estimated to be in Southeast Asia and the Western Pacific [7]. As the most common bacterial STI with 105.7 million new cases annually and 100.4 million adults infected at any point in time, Chlamydia trachomatis deserves particular attention [7]. In women aged 15-49 years, C. trachomatis prevalence rates in these WHO regions are cited as follows: 5.1 million (2.6\%) in Africa, 5 million (1.1\%) in Southeast Asia, and 20.5 million (4.3\%) in the Western Pacific [7].

While the global impact of STIs like C. trachomatis is felt most acutely by women in poor countries, the consequences may be magnified for pregnant women with potential risks to maternal and infant health. Although limited data exist, worldwide prevalence studies of $C$. trachomatis in pregnant women suggest similar if not higher prevalence rates than in nonpregnant women. Individual studies of pregnant 


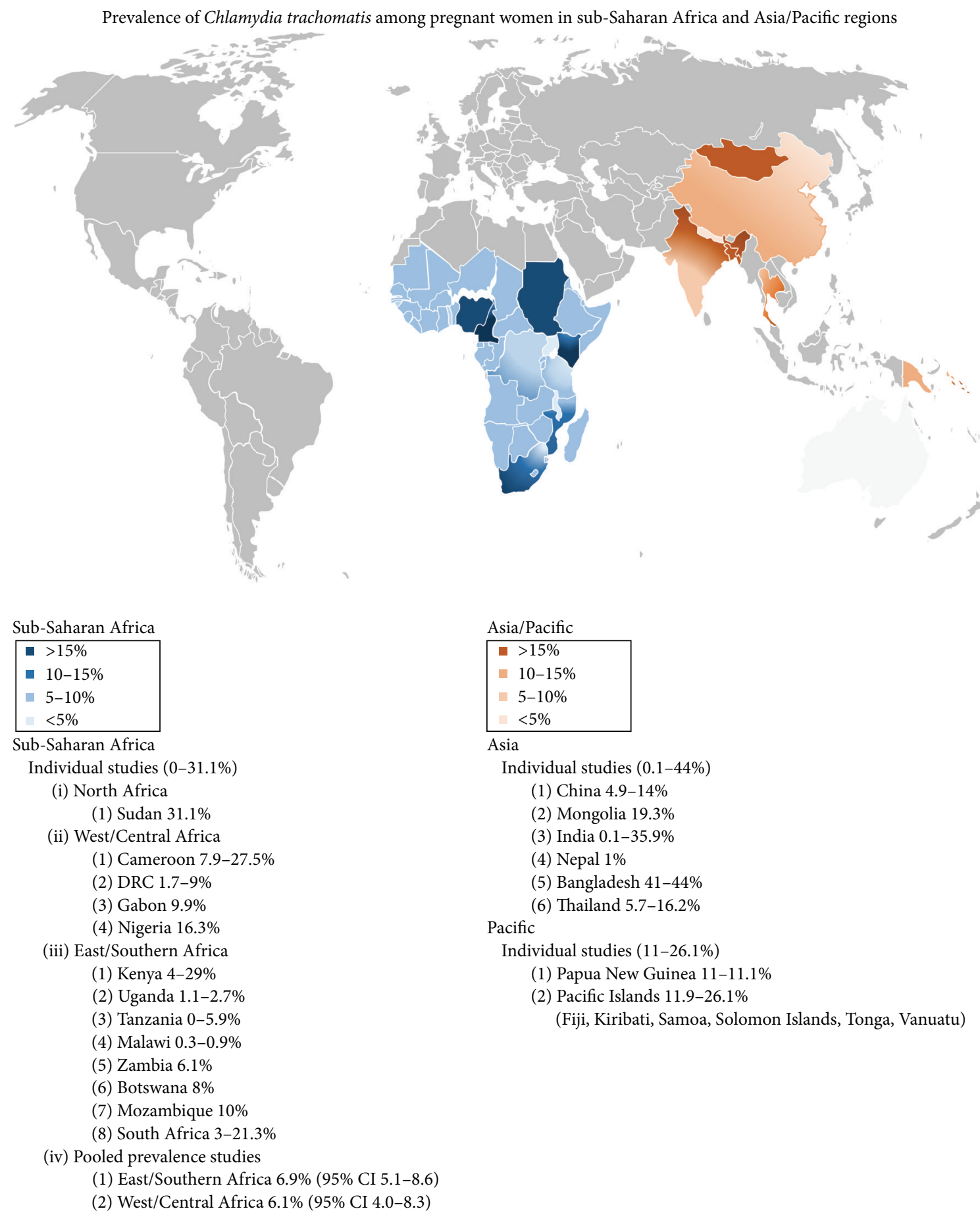

FIGURE 1: Chlamydia trachomatis in pregnant women in sub-Saharan Africa and Asia.

women in sub-Saharan Africa (Sudan, Cameroon, Democratic Republic of Congo (DRC), Gabon, Nigeria, Kenya, Uganda, Tanzania, Malawi, Zambia, Botswana, Mozambique, and South Africa) suggest prevalence rates of $0-31.1 \%$, while pooled prevalence rates are 6.9\% (95\% CI, 5.1-8.6) in East and Southern Africa and 6.1\% (95\% CI, 4.0-8.3) in West and Central Africa [8-29]. Other individual studies of pregnant women in China, Mongolia, India, Nepal, Bangladesh, Thailand, Papua New Guinea, and Pacific Islands (Fiji, Kiribati, Samoa, Solomon Islands, Tonga, and Vanuatu) reported rates of $4.9-14 \%, 19.3 \%, 0.1-35.9 \%, 1 \%, 41-44 \%, 5.7-16.2 \%, 11-11.1 \%$, and $11.9-26.1 \%$, respectively [30-51] (Figure 1).

HIV-infected pregnant women may also be at higher risk; one study of HIV-infected pregnant women found $C$. 
trachomatis prevalence rates of $21.3 \%$ for their South African subcohort [24]. Similar findings were seen in a study in Thailand that reported higher rates of chlamydial infection in HIV-infected versus HIV-uninfected pregnant women (16.2\% versus $9.1 \%)$ [50].

\subsection{Chlamydia trachomatis in Pregnancy: Exploring Adverse} Outcomes. As intracellular bacteria with an ability to exist in resting and infectious forms within human epithelial host cells, Chlamydia trachomatis presents a unique challenge to eradication [81, 82]. This ability to evade host detection and elimination also contributes to its ability to cause adverse outcomes among women. While it is often an asymptomatic infection in women, C. trachomatis is also an important cause of cervicitis, urethritis, and pelvic inflammatory disease (PID), which is an ascending infection of the uterus, fallopian tubes, or neighboring pelvic structures that can vary in presentation as asymptomatic endometritis, salpingitis, tuboovarian abscess, pelvic peritonitis, perihepatitis, or periappendicitis [81].

In addition, infection with $C$. trachomatis may pose special risks for pregnant women. Chlamydia trachomatis and other reproductive tract infections have long been suspected as risk factors for adverse pregnancy outcomes [83]. Further support comes from the fact that other Chlamydia species apart from C. trachomatis (C. pneumoniae and C. abortus) as well as Chlamydia-like emerging organisms (Waddlia and Parachlamydia) have also been linked with adverse pregnancy outcomes, especially for miscarriage, stillbirth, and preterm birth [84-86].

Both epidemiologic and experimental studies have suggested that chlamydial infection during pregnancy poses a risk for adverse outcomes such as miscarriage (pregnancy that ends spontaneously before the fetus has reached a viable gestational age of 24 weeks), stillbirth (fetal death at 28 or more weeks of gestation), and preterm birth (birth before 37 weeks' gestation) by either direct fetal infection, placental damage, or severe maternal illness. (Note that the gestational age cutoffs for stillbirths vary; in the USA, 20 weeks' gestational age is used; however, the International Classification of Diseases and Related Health Problems, 10th revision, uses the cutoff of 22 weeks' gestational age or birth weight of $500 \mathrm{~g}$; in contrast, the WHO uses a cutoff of 28 weeks or $1000 \mathrm{~g}$ because, in many low- and middle-income countries, many infants will not survive if born before 28 weeks' gestation [85$88]$ ). The mechanism by which chlamydial infection may lead to adverse outcomes in pregnancy is not well understood. It is thought that $C$. trachomatis may infect the fetus, triggering a harmful inflammatory response with cytokine release leading to miscarriage, premature rupture of membranes, or preterm labor or possibly causing a maternal inflammatory response that induces embryonic rejection due to homology of the chlamydial and human $60 \mathrm{kDa}$ heat shock proteins [85, 86, $89,90]$. It has also been hypothesized that these inflammatory responses to chlamydial heat shock protein (CHSP-60) may also be responsible for tubal damage that may lead to tubal infertility and ectopic pregnancy [91-93].

\section{Adverse Pregnancy Outcomes}

2.1. Miscarriage, Stillbirth, and Ectopic Pregnancy. Some have suggested that infections in general may account for up to $10-66 \%$ of late miscarriages and may be a more prominent risk factor for miscarriage in pregnant women in low- and middle-income countries [94, 95]. Genital tract infections such as $C$. trachomatis have been cited as a potential trigger of miscarriages [86, 94-97]. However, the strength of evidence linking STIs with miscarriage is most notable for syphilis and HIV [98-100].

Studies investigating the role that $C$. trachomatis may play in miscarriages have had mixed results, including a small meta-analysis of 4 studies that failed to support an association [32, 101-104]. Some studies have documented associations between miscarriage and prior chlamydial infection as demonstrated by anti-chlamydial IgG and IgA antibodies and detection of chlamydial DNA/antigen from products of conception and placentas of miscarriages [52, 85, 105, 106]; one study found that women with positive chlamydial serology were more likely to have miscarriages than controls (aOR 2.3, 95\% CI 1.1-4.9), and C. trachomatis DNA was more common in products of conception and the placenta in women with miscarriage than in controls (4\% versus $0.7 \%$, and $p=$ 0.026) [105]. Scarce data exist from sub-Saharan Africa and Asia regarding the role of $C$. trachomatis in miscarriage, apart from one study from China and another from India $[32,52]$ (Table 1).

While more global data on stillbirth exist in comparison to miscarriage, global stillbirth estimates remain uncertain due to the lack of accurate data. Since almost half of the world's 130 million births occur at home, global stillbirth estimates were nearly nonexistent before 2006 [87]. It has been estimated that almost $99 \%$ of stillbirths occur in low- and middle-income countries [87]. In regions such as South Asia and sub-Saharan Africa, rates may be as high as 32-34 per 1,000 births, which contrasts with that of 3.1 per 1,000 births in high-income countries [107-109].

Maternal infections are thought to be important causes of stillbirth, accounting for half of stillbirths in low- and middle-income and $10-25 \%$ in high-income countries [86, $110,111]$. Although published information on STIs other than syphilis is scarce, some studies have suggested that chlamydial infection may also play a role in stillbirths [100]. One such study found C. trachomatis antibodies in 33.3\% of mothers with stillbirths in comparison to $10.4 \%$ of mothers with live births $(p<0.0005)$ (note that stillbirth was defined as greater than 21 weeks' gestational age; based on some definitions such as the WHO definition of stillbirth, this would be classified as miscarriage as opposed to stillbirth) [112]; similar findings were reported in another large cohort of pregnant women, where chlamydial infection was a predictor for perinatal death $[106,113,114]$. Others have recovered C. trachomatis from the amniotic fluid and fetal lung and liver tissue from women suffering pregnancy loss with intact membranes [86, $106,115]$. Another retrospective study found that women with chlamydial infection prior to birth were at higher risk for stillbirth (aOR 1.40, 95\% CI 1.00-1.96) [116]. Only one individual study of chlamydial infection and stillbirth from Asia 


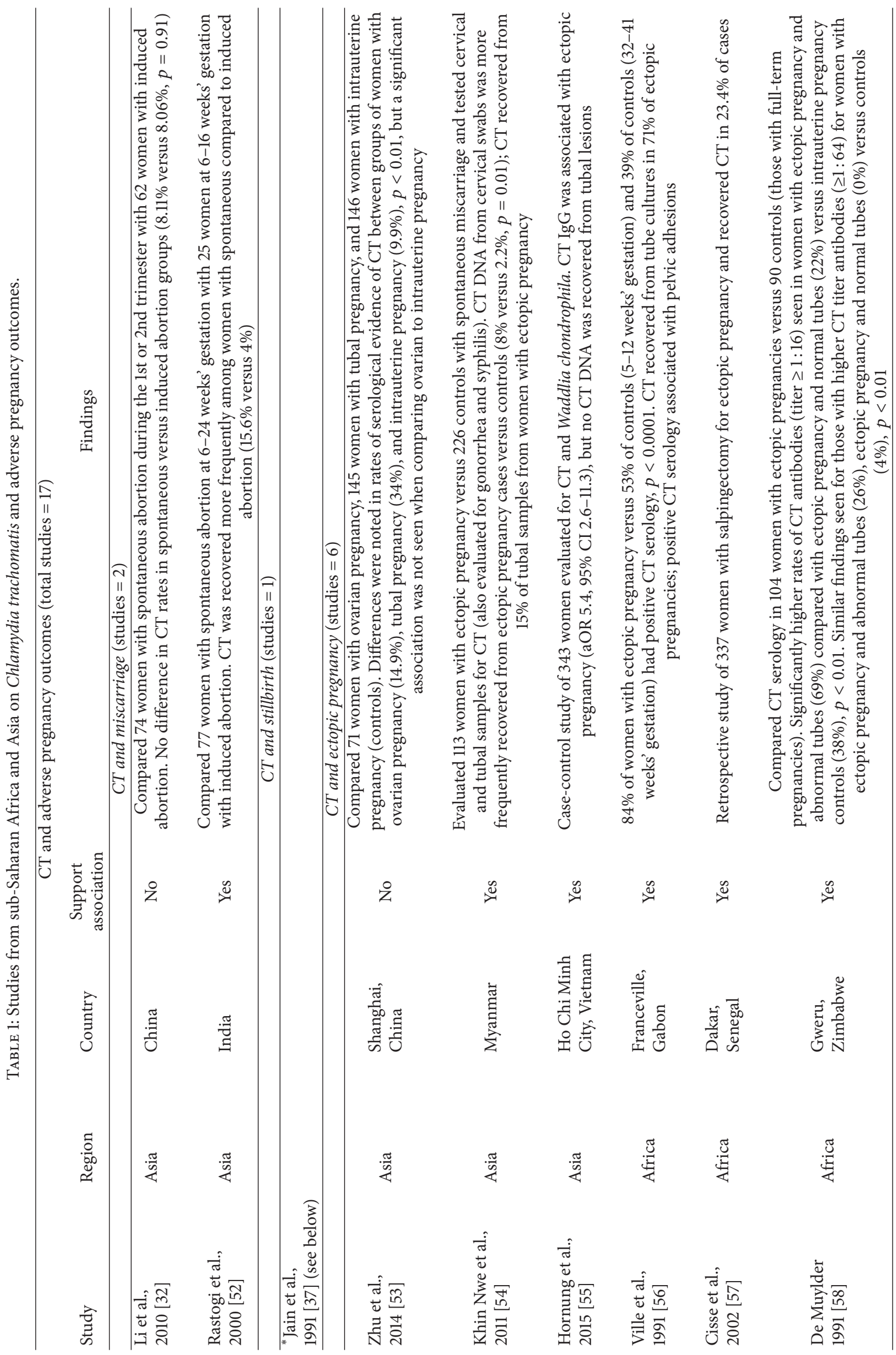




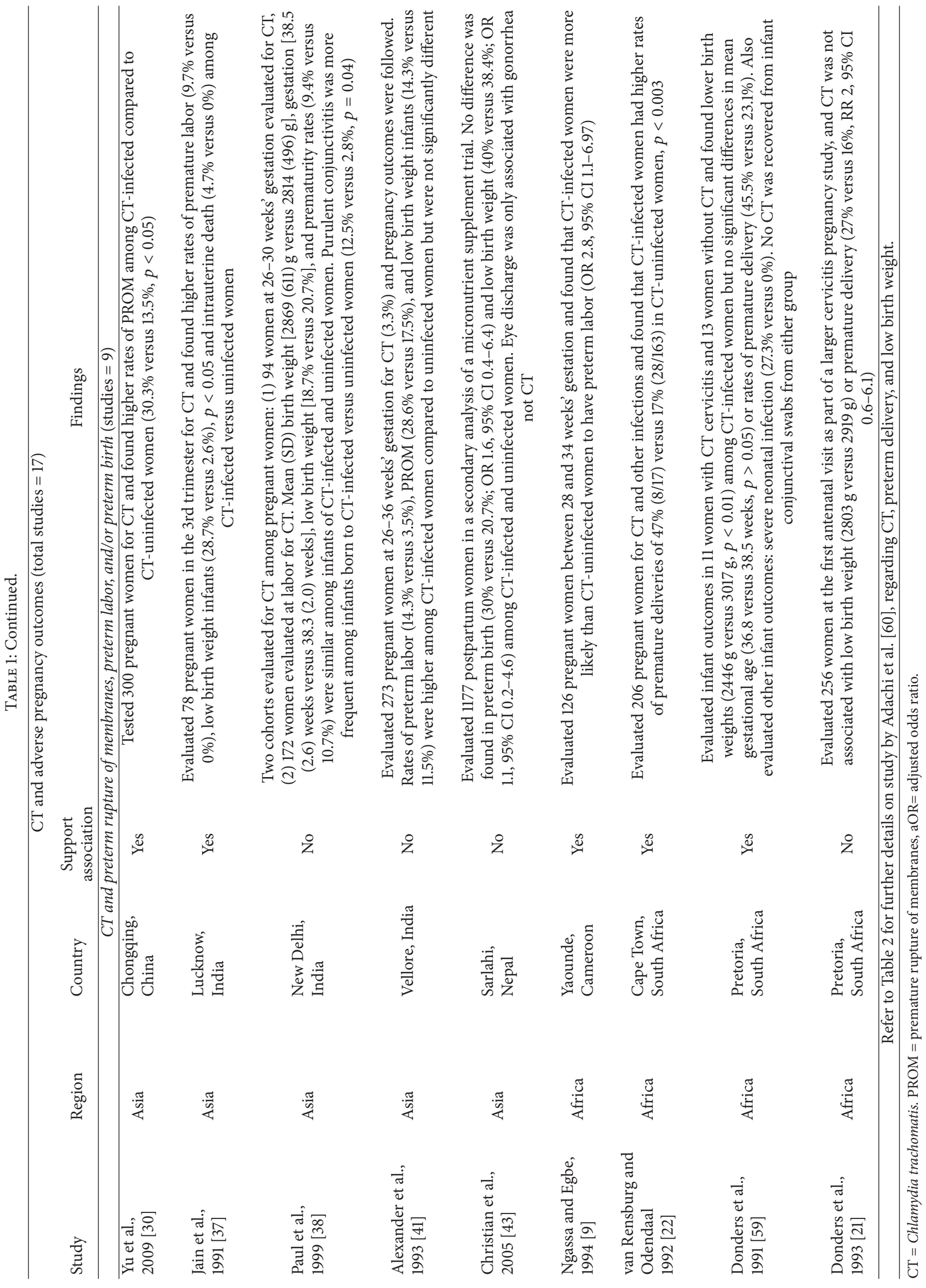




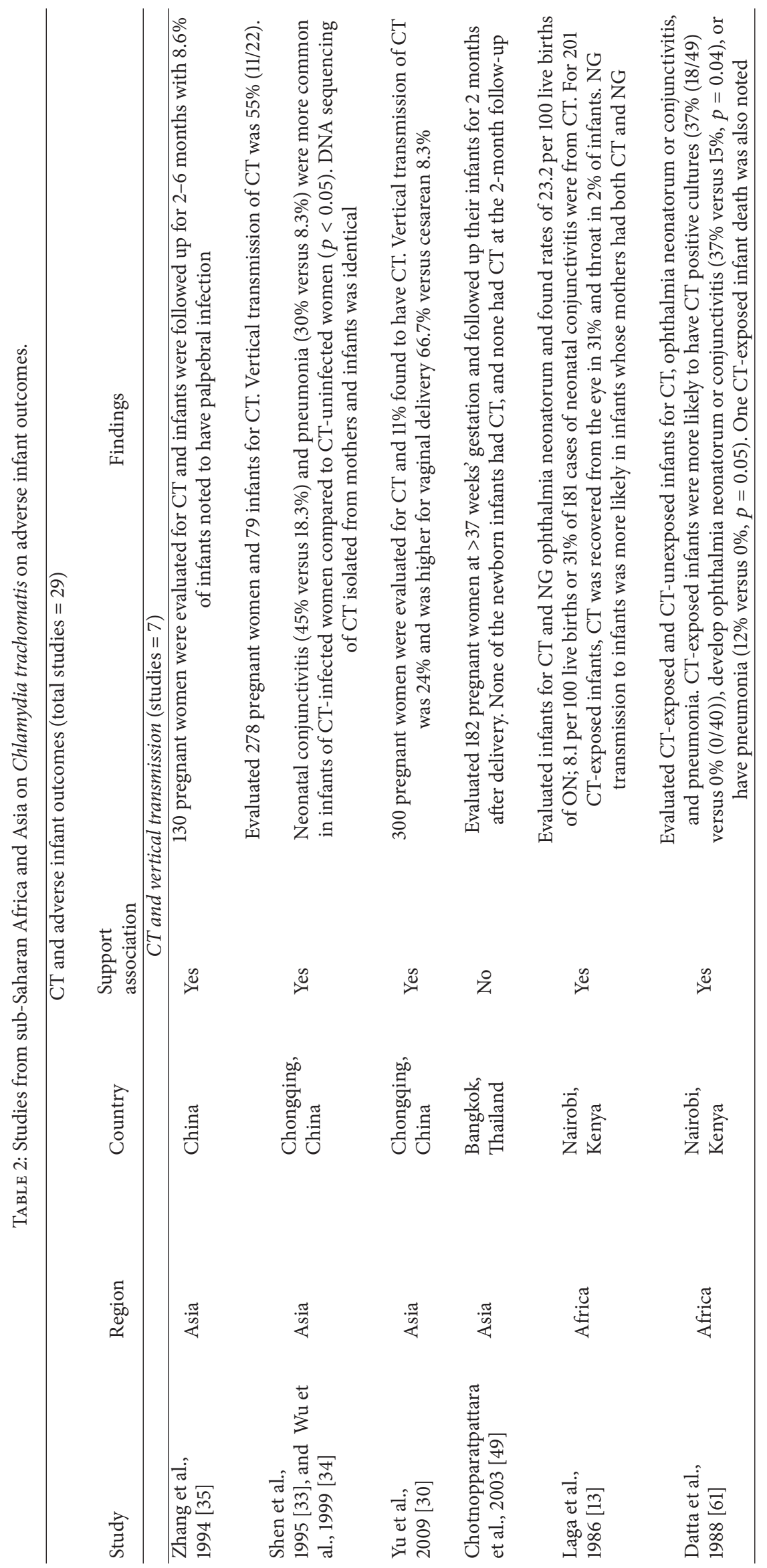









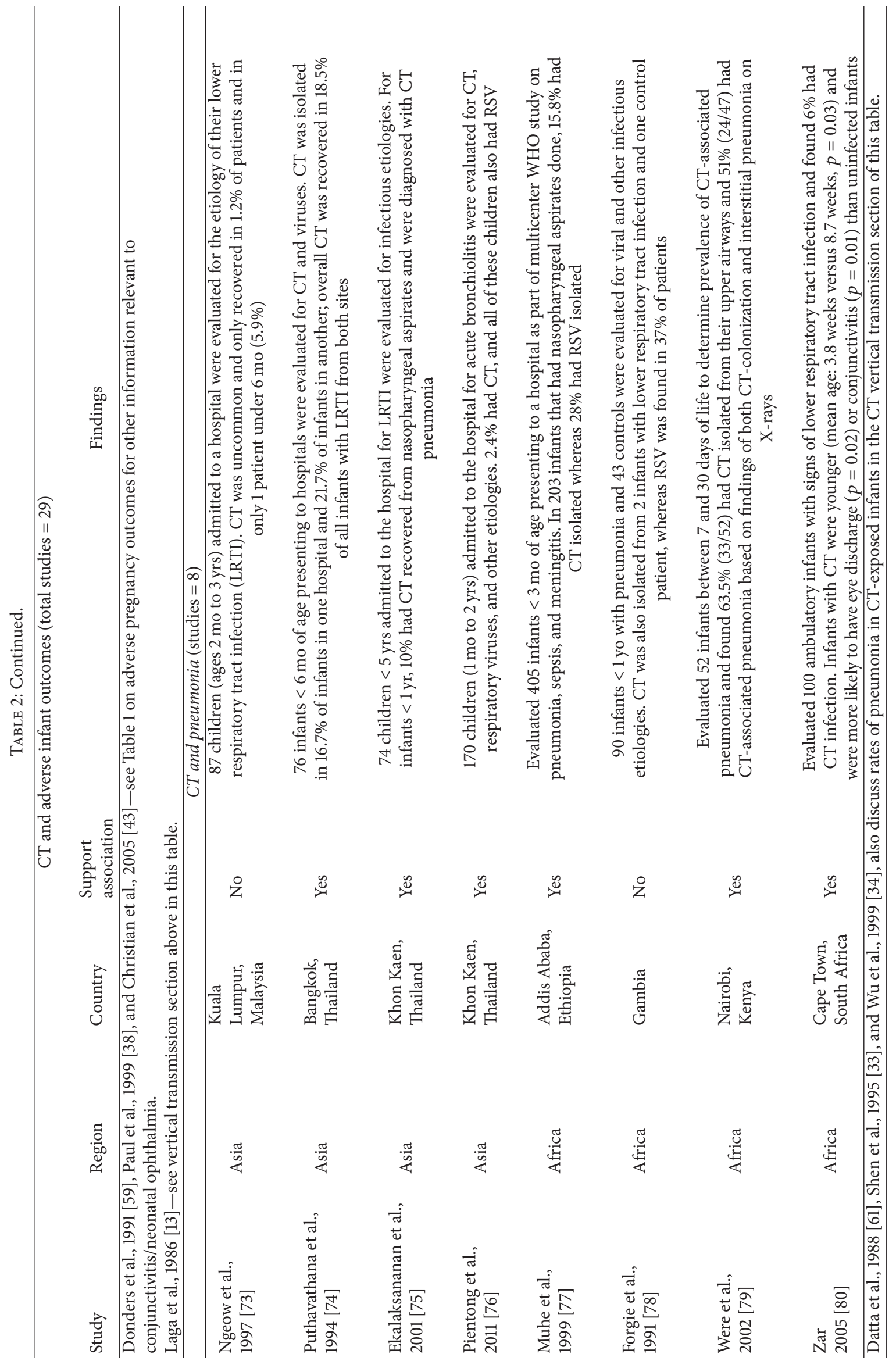




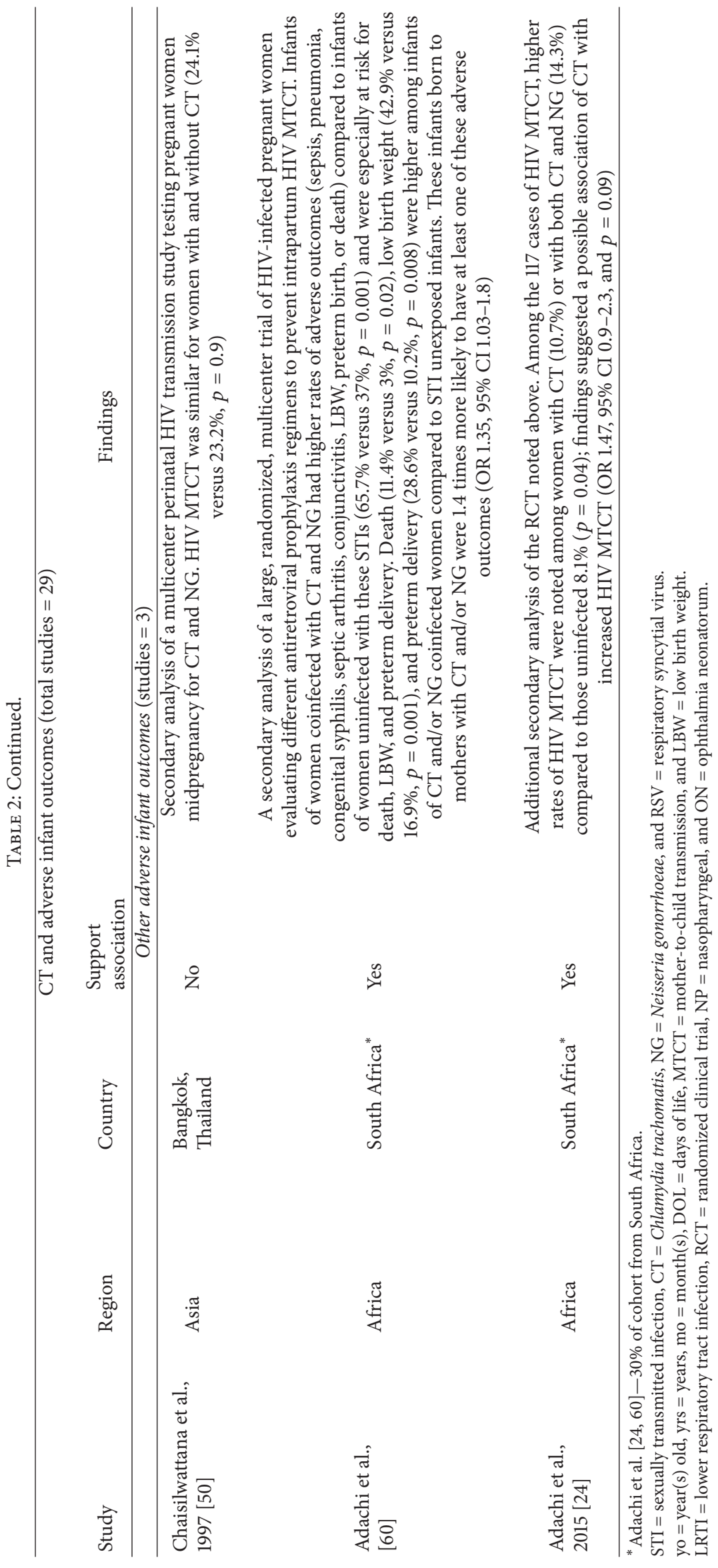


or sub-Saharan Africa was identified and reported higher rates of intrauterine death among Indian women with positive chlamydial serology (4.7\% versus $0 \%$ ) [37] (Table 1 ).

Ectopic pregnancy, which occurs when the blastocyst implants outside of the uterus endometrial cavity (in either the fallopian tubes, ovaries, or abdomen), may complicate 1$3 \%$ of pregnancies [92, 117-119]. Ectopic pregnancy can be a life-threatening condition and remains an important global cause of maternal morbidity and mortality due to associated complications such as tubal rupture and hemorrhage $[117,118$, 120-124]. Some studies from sub-Saharan Africa (Cameroon, Ghana, and Mozambique) have reported that ectopic pregnancy may account for 3.6-12.5\% of cases of maternal deaths [121-123].

Prior ascending genital tract infections leading to pelvic inflammatory disease have been considered risk factors for tubal damage that can lead to ectopic pregnancy and tubal infertility; some have suggested that genital infections may pose a threefold to fourfold increased risk of developing ectopic pregnancy $[118,119]$. The proposed association between genital tract infections, particularly Chlamydia trachomatis, and the development of ectopic pregnancy primarily results from epidemiological studies reporting recovery of chlamydial antibodies (including antibodies specific to $C$. trachomatis and chlamydial heat shock protein (CHSP-60)), antigenic material, and histologic evidence more frequently from women with ectopic pregnancies versus controls [93, $106,125-131]$.

In addition, the results from several studies from countries in sub-Saharan Africa (Gabon, Senegal, and Zimbabwe) and Asia (Myanmar and Vietnam) also suggest that $C$. trachomatis may be a risk factor for ectopic pregnancy [5458] (Table 1).

\subsection{Preterm Labor, Preterm Birth, and Low Birth Weight.} Globally, preterm birth has been identified as the single most important cause of perinatal morbidity and mortality, accounting for $27 \%$ of the nearly four million reported annual neonatal deaths; it is a risk factor for chronic lung disease, infections, and neurologic disabilities including intracranial hemorrhage, cerebral white matter damage, and cerebral palsy $[86,107,111,132,133]$. Around the world, preterm birth has also recently become the leading contributor to mortality for all children under five, not just neonates [134-136].

Worldwide studies have estimated that 14.9 million infants are born premature $[107,135,137]$. Estimates of preterm birth rates range from $5 \%$ in Europe to $18 \%$ in African nations with an average of $7.5 \%, 8.8 \%$, and $12.5 \%$ in more, less, and least developed regions $[107,135,137]$. Yet, it is in sub-Saharan Africa and South Asia, where over $60 \%$ of the preterm infants are born; India, China, Nigeria, Pakistan, and Indonesia have the highest numbers of preterm births in the world [135].

While the vast majority of preterm births occur secondary to spontaneous preterm labor, preterm birth is often the end product of numerous causal factors [137]. Some have suspected that genital tract infections may be a risk factor for preterm delivery. Symptomatic and chronic intrauterine infection with organisms like C. trachomatis may be important contributing factors with some suggesting that genital tract infections may contribute to as many as $40 \%$ of preterm birth cases $[86,138]$.

While some studies have shown no significant association between C. trachomatis and preterm birth [21, 38, 41, 43, 139144], the majority of studies reviewed suggest that chlamydial infections increase the risk for preterm delivery and/or low birth weight $[9,22,30,37,59,60,84,112-114,116,132,145-$ 164]. Those findings are well-summarized in a 12-study metaanalysis reporting that chlamydial infection during pregnancy was associated with an increased risk of preterm labor (RR 1.35, 95\% CI 1.11-1.63), low birth weight (RR 1.52, 95\% CI 1.24-1.87), and perinatal mortality (RR 1.84, 95\% CI 1.15-2.94) [101].

Prospective studies have found that placental inflammation (OR 2.1, 95\% CI 1.2-3.5) and chlamydial DNA were more frequently isolated from placentas of women who delivered at or before 32 weeks [132]. Similarly, other studies have suggested that maternal chlamydial infection may increase the risk of preterm delivery (RR 1.46, 95\% CI 1.08-1.99) and premature rupture of membranes (RR 1.50, 95\% CI 1.03-2.17) [162], and a large population-based prospective study of 4,055 pregnant women reported that chlamydial infection was associated with more than a fourfold increased risk of early preterm delivery (OR 4.35, 95\% CI 1.3-15.2) [164]. Another frequently cited case-control study, which analyzed urine specimens for C. trachomatis from 190 women with preterm birth, observed that chlamydial-infected women at 24 weeks of pregnancy were 2 times more likely to have spontaneous preterm birth $<37$ weeks (OR 2.2, 95\% CI 1.03-4.78) and three times more likely to have an early spontaneous preterm birth $<35$ weeks of gestation (OR 3.2, 95\% CI 1.08-9.57) [163]. However, support of those findings was not observed in another secondary analysis by the same authors [144].

Despite the substantial burden of preterm birth estimated in sub-Saharan Africa and Asia, few published studies of $C$. trachomatis and related outcomes of preterm labor and/or low birth weight from countries in these regions exist. Among the studies that could be identified, the majority seem to support a role for $C$. trachomatis in preterm birth and similar outcomes. Two of the twelve studies included in the metaanalysis discussed above were from Asia [30,37]. One was a study of 300 pregnant women in China, which found higher rates of premature rupture of membranes in women with chlamydial infection compared to those without (30.3\% versus $13.5 \%, p<0.05$ ) [30]. The other was a small study of 78 Indian women, which observed that women with positive $C$. trachomatis serology had higher rates of preterm labor $(9.7 \%$ versus $0 \%$ ) and low birth weight infants (28.7\% versus $2.6 \%$ ) compared to those with negative serology [37]. Several other studies from South Africa $[22,59]$ support those findings as well as a study from Cameroon, where pregnant women with chlamydial infection were almost three times more likely to have preterm labor (OR 2.8, 95\% CI 1.1-6.97) [9]. In contrast, a few studies, including ones from India, Nepal, and South Africa, did not find significant associations, possibly due to issues with sample size and/or low prevalence of $C$. trachomatis [21, 38, 41, 43] (Table 1). 
TABle 3: Studies from sub-Saharan Africa and Asia on Chlamydia trachomatis screening and treatment in pregnancy to prevent adverse pregnancy and infant outcomes.

\begin{tabular}{lccc}
\hline \multicolumn{4}{c}{ CT screening/treatment to prevent adverse pregnancy and infant outcomes (total studies $=2)$} \\
\hline Study & \multicolumn{3}{c}{ CT screening/treatment to prevent adverse pregnancy outcomes (studies = 2) } \\
\hline
\end{tabular}

\begin{tabular}{|c|c|c|c|c|}
\hline & Kegior & itry & benefit & \\
\hline $\begin{array}{l}\text { Gray et al., } \\
2001 \text { [26] }\end{array}$ & Africa & Rakai, Uganda & Yes & $\begin{array}{c}\text { Evaluated } 2070 \text { pregnant women in an analysis from a } \\
\text { cluster-randomized STI presumptive treatment trial with } \\
\text { azithromycin, cefixime, and metronidazole (also included } \\
\text { benzathine penicillin G if syphilis serology was positive) } \\
\text { versus placebo. Found reduction in CT/NG (RR } 0.43,95 \% \text { CI } \\
0.27-0.68 \text { ) and other STIs. Found reduction in low birth } \\
\text { weight (RR 0.68, 95\% CI 0.53-0.86), preterm delivery (RR } \\
0.77,95 \% \text { CI } 0.56-1.05 \text { ), neonatal death, (RR } 0.83,95 \% \text { CI } \\
0.71-0.97 \text { ), and infant ophthalmia (RR } 0.37,95 \% \text { CI } \\
0.20-0.70 \text { ). }\end{array}$ \\
\hline
\end{tabular}

$$
0.20-0.70) \text {. }
$$

Erythromycin was given to $17 \mathrm{CT}$-infected pregnant women and compared to 42 untreated CT-infected women lost to follow-up and 269 women without CT. CT-infected and

\begin{tabular}{|c|c|c|}
\hline $\begin{array}{l}\text { Rastogi et al., } \\
2003 \text { [39] }\end{array}$ & Asia & $\begin{array}{l}\text { New Delhi, } \\
\text { India }\end{array}$ \\
\hline
\end{tabular}
treated women had infants with higher mean gestational ages at the time of delivery ( 35.5 versus 33.1 weeks, $p<0.05$ ) and higher birth weights (2200 versus $2113.3 \mathrm{~g}$, although not significant) in comparison to untreated women. Stillbirths were higher in CT-infected and untreated women in comparison to the CT-uninfected (11.5\% versus $4.7 \%$ ), and $0 \%$ in CT-infected treated women.

$\frac{0 \% \text { in CT-infected treated women. }}{\text { CT screening/treatment to prevent adverse infant outcomes (studies }=0)}$

\footnotetext{
${ }^{*}$ Study by Gray et al. [26] includes some adverse infant outcomes-neonatal death and infant ophthalmia as noted above. $\mathrm{CT}=$ Chlamydia trachomatis, $\mathrm{NG}=$ Neisseria gonorrhoeae, $\mathrm{STI}=$ sexually transmitted infection.
}

A recent secondary analysis of $1373 \mathrm{HIV}$-infected pregnant women (approximately 30\% of the cohort included South African women with a high prevalence of both C. trachomatis and Neisseria gonorrhoeae) also demonstrated significant differences in rates of infant low birth weight $(42.9 \%$ versus $16.9 \%, p=0.001)$ and preterm birth $(28.6 \%$ versus $10.2 \%, p=0.008)$ for women with and without these STIs $[60,165]$ (Table 2).

2.3. Prevention of Adverse Pregnancy Outcomes. Given that Chlamydia trachomatis and other STIs are curable infections, many pregnancy and neonatal complications could potentially be prevented with antenatal screening programs that accurately identify and treat infected women $[153,154,166]$.

However, only a small number of studies have attempted to evaluate the potential benefits of chlamydial antenatal screening and treatment to prevent adverse pregnancy outcomes such as low birth weight, preterm delivery, preterm labor, or premature rupture of membranes $[26,39,144,152-$ $154,166,167]$. These studies varied with respect to study design, method of testing, collected specimen type, gestational age at testing, number of other STIs evaluated, and antibiotic used for treatment. All of those studies except one [144] provided some level of support that screening and treatment of chlamydial infection in pregnancy could improve rates of adverse pregnancy outcomes [26, 39, 152-154, 166,
167]. Only two of the studies took place outside of the USA, including one in Uganda and one in India [26, 39] (Table 3).

Four of those studies presented the strongest evidence suggesting that chlamydial treatment may lead to improved pregnancy outcomes $[152-154,166]$. Some of the studies found significant reductions in preterm birth [13.9\% to $2.9 \%$, $p=0.00002$, OR 0.16, 95\% CI 0.06-0.47] [153]; premature rupture of membranes [ $5.2 \%$ to $2.9 \%$ (OR 0.56 , $95 \%$ CI $0.37-$ 0.85 ) [154], $20.3 \%$ to $7.4 \%$ (OR 0.31, 95\% CI 0.14-0.69) [153], and $50 \%$ to $0 \%$ (RR $0.4,95 \%$ CI $0.2-0.8$ )] [152]; and/or low birth weight infants [17\% to $8 \%, p=0.04$ [166], and $19.6 \%$ to $11 \%, p<0.0001$ ] [154] when comparing women treated for chlamydial infection versus untreated or persistently infected women. Yet, those studies also had limitations including the antibiotic regimen used, failure to directly treat partners, unknown usage of other antibiotics, and failure to see significant findings in one of the study's preliminary analyses.

\section{Adverse Infant Outcomes}

Studies dating back to the 1970s demonstrated that Chlamydia trachomatis could be vertically transmitted at the time of delivery from mothers to infants [168]. Earlier studies estimated that approximately $50-70 \%$ of infants born to mothers with untreated genital chlamydial infection will become infected with $30-50 \%$ developing conjunctivitis and $10-20 \%$ 
developing pneumonia [169-171]. In studies from subSaharan Africa (2 from Kenya) and Asia (4 from China, 1 from Thailand), most have found similarly high rates of $C$. trachomatis vertical transmission $[13,30,33-35,49,61]$ (Table 2).

The 1980s implementation of antenatal screening and treatment for chlamydial infection in the USA significantly lowered the incidence of both neonatal chlamydial pneumonia and conjunctivitis, which was previously the most common cause of neonatal conjunctivitis there [169]. Due to the lack of similar initiatives in other countries, chlamydial conjunctivitis and pneumonia continue to be prevalent worldwide $[169,172]$. Compared to the sparse data on adverse pregnancy outcomes and C. trachomatis from sub-Saharan Africa and Asia, more published information documenting infant chlamydial infection from countries in these regions exists (Table 2).

3.1. Conjunctivitis. Classically, chlamydial conjunctivitis develops 5-14 days after birth with symptoms ranging from mild conjunctival injection with discharge to severe mucopurulent conjunctivitis with chemosis and pseudomembrane formation $[173,174]$. Although vision loss is rare, consequences of untreated infection include persistent conjunctivitis, pannus (neovascularization of the cornea), and scarring [173]. Differing from gonococcal conjunctivitis, chlamydial conjunctivitis cannot be effectively prevented using antibiotic or silver nitrate ocular prophylaxis $[169,174,175]$.

Existing studies from sub-Saharan Africa and Asia also suggest that $C$. trachomatis remains a frequent cause of neonatal conjunctivitis. Studies of infants from sub-Saharan Africa (Cameroon, Gabon, Gambia, and Kenya) have demonstrated that C. trachomatis remains a common etiology of ophthalmia neonatorum and may account for up to $33 \%$ of cases $[13,68-72]$. Studies from China have estimated that chlamydial conjunctivitis occurs in 4 per 1,000 live births [64, 169]. Apart from one study from Singapore [66], other studies from Asia (China, Cambodia, and Thailand) also report frequently isolating C. trachomatis in $12.2 \%-60 \%$ of infants with conjunctivitis or ophthalmia neonatorum [62-65, 67] (Table 2).

3.2. Pneumonia. Being often underdiagnosed, chlamydial pneumonia tends to be a subacute, afebrile infection, typically occurring in infants between 1 and 3 months of age [174]. In younger infants, especially in the premature, chlamydial pneumonia can be more severe, associated with apnea, and may require hospitalization in $25 \%$ [173, 176]. Although associated mortality is supposedly rare, untreated pneumonia can persist for several weeks and may lead to poor feeding and diminished weight gain; some have suggested that infection may lead to asthma and chronic lung disease later in life $[173,177,178]$.

As in studies from other countries, existing studies of infants from sub-Saharan Africa have suggested that C. trachomatis may be a frequent but underrecognized pathogen in lower respiratory tract infections including pneumonia [169, 179]. Most studies evaluating infants from Ethiopia, Kenya, and South Africa found that $C$. trachomatis was a frequent isolate $(6-51 \%)$ from infants with lower respiratory tract infections including pneumonia [77-80]. The study from Ethiopia found that C. trachomatis was the 2 nd most common infectious etiology (15.8\%) after Respiratory Syncytial Virus (RSV) (28\%) in infants less than 3 months presenting with pneumonia; similar findings were also reported in a study of infants in Netherlands (7\%) and a study of infants in Thailand (18.5\%) [74, 77, 169, 179]. Excluding the findings of a small study of Malaysian children with pneumonia, other studies from Asia (Thailand) also emphasized the importance of chlamydial infection in young children with pneumonia as well as a possible coinfection pathogen for those with RSV bronchiolitis [73, 75, 76] (Table 2).

3.3. Other Adverse Infant Outcomes. Beyond the welldocumented risks of neonatal chlamydial infection (conjunctivitis and/or pneumonia) associated with maternal chlamydial infection in pregnancy, some studies suggest other consequences of untreated STIs in pregnancy. A few studies have observed increased rates of neonatal and infant death with STIs such as C. trachomatis in pregnancy [60, 101, 146, $165,180,181$ ] (Table 2).

Possible Risk Factor for HIV Mother-to-Child Transmission (MTCT). Concern also exists that STIs may increase the risk of HIV mother-to-child transmission (MTCT), for early studies have suggested that genital infections like C. trachomatis may lead to increased cervicovaginal shedding of HIV and chorioamnionitis [182-186]. However, few published studies have explored the effect that STIs such as C. trachomatis in pregnancy may have on HIV MTCT. In one of the HIV Prevention Trials Network (HPTN) 040 substudies of $1373 \mathrm{HIV}$-infected pregnant women, the rates of HIV MTCT among women infected with C. trachomatis (10.7\%) were significantly higher compared to those uninfected (8.1\%); further analysis also suggested a possible association of chlamydial infection and increased HIV MTCT (OR 1.47, 95\% CI 0.9-2.3; $p=0.09$ ) [24] (Table 2).

Yet, those findings of increased risk of HIV MTCT were not observed in a smaller study from Thailand of $222 \mathrm{HIV}$ infected pregnant women in spite of a high prevalence of chlamydia (16.2\%) [50]. The findings of the HPTN 040 substudy were also not supported by findings of earlier randomized trials of empiric STI treatment during pregnancy including the well-known Rakai study in Uganda and the HPTN 024 study that took place in Zambia, Malawi, and Tanzania; both studies failed to demonstrate that empiric antibiotics effective against $C$. trachomatis had any impact on reducing the rates of HIV MTCT $[26,184]$. Both studies had low rates of C. trachomatis in their study populations $(1.1-2.7 \%$ and $2.5 \%)$, which may have contributed to the lack of findings $[15,26,183,184]$.

3.4. Prevention of Infant Chlamydial Infection. Screening and treatment of chlamydia in pregnancy has been considered by some as the only effective means of preventing chlamydial pneumonia, conjunctivitis, or colonization in infants [169]. Yet, in the existing literature, only a handful of primary 
studies have provided information regarding the effect of screening and treatment on prevention of neonatal chlamydial infection, and none of these studies took place in subSaharan Africa or Asia [141, 168, 170, 187-190]. Almost all of the studies used erythromycin as the primary therapeutic intervention or as part of the interventions evaluated, and nearly all used chlamydial cervical culture to evaluate for infection in women. Wide variability was noted in study design, cohort size, chlamydia prevalence, time of testing, time of therapeutic intervention, and methods used to evaluate for infant chlamydial infection.

All of these studies, except one small study of 21 women, found significant differences in rates of infant chlamydia for women treated for chlamydial infection during pregnancy [190]. Two observational studies from the mid-1980s in the USA provided the strongest evidence that antenatal chlamydial treatment with erythromycin may decrease chlamydial infection in infants $[168,170]$. These studies observed significantly lower rates of infant chlamydial infection for those born to women receiving treatment with erythromycin as opposed to no treatment for chlamydia; infant chlamydial infection decreased from 50\% (12/24) to 7\% (4/59) $(p<$ $0.001)$ in one and from $23.8 \%(5 / 21)$ to $0 \%(0 / 16)(p<0.04)$ with treatment in the other. Infants of untreated women were also more likely to have symptomatic infection with conjunctivitis and pneumonia. These studies were not without limitations, which included considerable numbers of women and infants lost to follow-up and the use of a nonstandardized erythromycin treatment regimen in one of the studies.

\section{Preventing Chlamydial Adverse Pregnancy and Infant Outcomes: Vaccine Development and Antenatal Screening and Treatment}

4.1. Global and Historical Challenges. Worldwide prevention of adverse pregnancy and neonatal outcomes from Chlamydia trachomatis has been impeded by two primary factors: lack of an effective human vaccine and lack of progressive, targeted screening/treatment recommendations for pregnant women. The development of a safe and effective vaccine would likely provide the best hope of reducing the global burden of disease from C. trachomatis, especially its associated maternal and infant morbidity that can even result from asymptomatic infections. Yet, historically, the development of a C. trachomatis vaccine has been riddled with challenges, which were noted even with the early human vaccine trials in the 1960s [191]. These early immunization trials of whole organism preparations had issues with waning immunity and raised concerns about the risks of immunopathology and the potential for reversion back to wild-type strains [192]. Vaccine efforts since then have focused on other targets such as major outer membrane proteins (MOMP) and chlamydial outer membrane complex (COMC) proteins while hunting for alternative options [192-194]. The use of new candidate antigen targets such as polymorphic membrane proteins (PMPs), incorporation of additional promising vaccine targets such as dendritic cells, and the discovery of novel, less toxic adjuvants may provide greater opportunities to develop a successful human vaccine in the upcoming years $[192,194-$ 196].

Historically, considerable obstacles have also thwarted efforts to improve global chlamydial screening and treatment practices for pregnant women. In spite of improved detection of chlamydial infections with molecular-based nucleic acid testing, more patient friendly specimen collection methods, and simple, highly effective, one-dose oral treatment regimens, few countries around the world have made Chlamydia trachomatis screening and treatment a priority for pregnant women [197-201]. While some such as the USA have recommended universal $C$. trachomatis screening and treatment for all pregnant women or those at high risk since the 1980s, this is not standard practice globally $[197,202,203]$.

In low- and middle-income countries including those in sub-Saharan Africa and Asia, routine C. trachomatis screening during pregnancy has been previously hindered by limited awareness and lack of access to diagnostic methods [2, 7]. Traditionally, in resource-limited settings, the diagnosis of C. trachomatis and other STIs has focused on a "syndromic approach," which still remains endorsed by the WHO. This "syndromic approach" is notorious for its low sensitivity (30$80 \%$ ), performing particularly poor for C. trachomatis detection, which is typically asymptomatic [5, 14, 29, 204-206]. Those findings were emphasized in a recent South African study of 1480 women that found that more than $50 \%$ of $C$. trachomatis and other STIs were asymptomatic [23].

4.2. Antenatal Chlamydial Screening. Early successes of integrating antenatal screening and treatment of syphilis with existing HIV prevention of mother-to-child transmission (PMTCT) programs have shown the potential to expand such programs to include screening and treatment of other STIs such as C. trachomatis. Studies, particularly from China, have highlighted the ability for countries to lead rapid antenatal screening scale-up interventions. Some Chinese provinces have demonstrated near-universal screening rates for HIV, hepatitis B, and syphilis with significant reductions in congenital syphilis cases as well as adverse pregnancy outcomes including miscarriage, premature delivery, and stillbirth [207-209].

Need for Point-of-Care Testing. Much of the tolerance for the continued reliance on the "syndromic approach" to address $C$. trachomatis and other STIs in resource-limited countries has been a result of the cost and infrastructure required for the implementation of current testing methods used in resource rich countries.

Since C. trachomatis is an intracellular organism, older methods of identification relied on culture and enzyme immunoassay, which are labor intensive and demand considerable training, laboratory resources, and costs [210]. Currently the recommended tests for the detection of $C$. trachomatis are nucleic acid amplification tests (NAATs) [211, 212]. NAATs for C. trachomatis have high specificity (98-100\%) and high sensitivity (95\%) and can be used on noninvasive specimens such as urine and self-collected vaginal swabs [210]. 
With the introduction of NAATs for the detection of HIV and Mycobacterium tuberculosis in most countries around the world, the use of NAATs for C. trachomatis detection is highly feasible, even though they are not considered "point-of-care" (POC) tests [213]. Among the newer nucleic acid testing platforms recently developed is the Cepheid GeneXpert CT/NG assay, which has been considered a "nearpatient" testing method but not truly rapid ( $<20$ minutes) or of low cost [213]. It uses real-time PCR with a cartridge assay and features easy specimen loading with results in 90 minutes along with a record of excellent sensitivity and specificity (9798.7\% and 99.4-99.9\%).

The currently available POC tests for C. trachomatis are mainly poorly sensitive optical immunoassays (OIA) such as Inverness (previously BioStar), Clearview Chlamydia, QuickVue, Chlamydia Rapid Test, and OneStep and magnetic immunochromatographic tests that utilize rapid platforms based on antigen/antibody interactions [213]. One study of women tested in clinics in the Philippines, which compared a C. trachomatis POC test with a NAAT, found extremely poor sensitivities (12.5-19.4\%); poor sensitivity of C. trachomatis POC testing was also found in a study in six urban cities in China (32.8-49.7\%) [214, 215].

\section{Conclusion}

Untreated STIs in pregnancy, particularly Chlamydia trachomatis, continue to negatively impact the health of women and infants worldwide given the lack of a C. trachomatis vaccine and lack of adequate STI screening and treatment policies in most countries. There exists a great need to develop an effective chlamydial vaccine and to also incorporate antenatal screening for STIs such as C. trachomatis and Neisseria gonorrhoeae and possibly others such as Group B Streptococcus (GBS) and hepatitis B with existing networks currently conducting successful HIV and syphilis antenatal screening [216]. Studies from Zambia and China have suggested that an integrated approach to antenatal care that builds on existing HIV prevention of mother-to-child transmission (PMTCT) platforms has multiple benefits beyond just reduction in HIV vertical transmission; it capitalizes on the ability to address other important infections in pregnancy and increases antenatal care attendance $[217,218]$.

While few high-quality studies have investigated the benefit of antenatal chlamydial screening and treatment, the collective evidence appears to support the possibility of benefits for such an intervention. Large-scale, randomized clinical trials to investigate the true impact and cost-effectiveness of screening and treatment initiatives to improve pregnancy and infant outcomes are urgently needed. Hopefully, the continued evolution of better evidence and increasing availability of C. trachomatis detection assays will eventually persuade policy makers to address this neglected problem of STI screening and treatment in pregnancy [197, 219-221].

We can no longer afford to fail to invest in the sexual and reproductive health of women. The problem of STIs in pregnancy is a health issue affecting women, children, and adolescents. Building the evidence base for screening and treatment of STIs like Chlamydia trachomatis in pregnancy should be made a global priority because the health of "every woman, every child" matters $[3,4]$.

\section{Competing Interests}

The authors declare that they have no competing interests.

\section{Authors' Contributions}

Kristina Adachi, Karin Nielsen-Saines, and Jeffrey D. Klausner have collaborated to perform the literature search, paper selection, and the writing and development of this paper.

\section{References}

[1] A. Glasier, A. M. Gülmezoglu, G. P. Schmid, C. G. Moreno, and P. F. Van Look, "Sexual and reproductive health: a matter of life and death," The Lancet, vol. 368, no. 9547, pp. 1595-1607, 2006.

[2] World Health Organization, Global Strategy for Prevention and Control of Sexually Transmitted Infections: 2006-2015, World Health Organization, Geneva, Switzerland, 2006.

[3] United Nations, Saving Lives, Protecting Futures: Progress Report on the Global Strategy for Women's and Children's Health, United Nations, 2015.

[4] United Nations, The Global Strategy for Women's, Children's, and Adolescents' Health (2016-2030), United Nations, 2015.

[5] P. Mayaud and D. Mabey, "Approaches to the control of sexually transmitted infections in developing countries: old problems and modern challenges," Sexually Transmitted Infections, vol. 80, no. 3, pp. 174-182, 2004.

[6] World Bank, Reproductive Health Action Plan 2010-2015: Better Health for Women, Men, Adolescents, and Children, Human Development Network, 2014.

[7] World Health Organization Department of Reproductive Health Research, Global Incidence and Prevalence of Selected Curable Sexually Transmitted Infections-2008, World Health Organization Department of Reproductive Health Research, Geneva, Switzerland, 2012.

[8] Z. A. Abdelaziz, M. E. Ibrahim, N. E. Bilal, and M. E. Hamid, "Vaginal infections among pregnant women at Omdurman Maternity Hospital in Khartoum, Sudan," Journal of Infection in Developing Countries, vol. 8, no. 4, pp. 490-497, 2014.

[9] P. C. Ngassa and J. A. Egbe, "Maternal genital Chlamydia trachomatis infection and the risk of preterm labor," International Journal of Gynecology and Obstetrics, vol. 47, no. 3, pp. 241-246, 1994.

[10] R. Kinoshita-moleka, J. S. Smith, J. Atibu et al., "Low prevalence of HIV and other selected sexually transmitted infections in 2004 in pregnant women from Kinshasa, the Democratic Republic of the Congo," Epidemiology and Infection, vol. 136, no. 9, pp. 1290-1296, 2008.

[11] G. Beaujean and I. Willems, "Prevalence of Chlamydia trachomatis infection in pregnant women in Zaire," Genitourinary Medicine, vol. 66, no. 2, pp. 124-125, 1990.

[12] B. Vuylsteke, M. Laga, M. Alary et al., "Clinical algorithms for the screening of women for gonococcal and chlamydial infection: evaluation of pregnant women and prostitutes in Zaire," Clinical Infectious Diseases, vol. 17, no. 1, pp. 82-88, 1993.

[13] M. Laga, H. Nzanze, R. C. Brunham et al., "Epidemiology of ophthalmia neonatorum in Kenya," The Lancet, vol. 328, no. 8516, pp. 1145-1149, 1986. 
[14] G. Marx, G. John-Stewart, R. Bosire, D. Wamalwa, P. Otieno, and C. Farquhar, "Diagnosis of sexually transmitted infections and bacterial vaginosis among HIV-1-infected pregnant women in Nairobi," International Journal of STD \& AIDS, vol. 21, no. 8, pp. 549-552, 2010.

[15] S. Aboud, G. Msamanga, J. S. Read et al., "Genital tract infections among HIV-infected pregnant women in Malawi, Tanzania and Zambia," International Journal of STD \& AIDS, vol. 19, no. 12, pp. 824-832, 2008.

[16] P. Mayaud, G. Ka-Gina, J. Cornelissen et al., "Validation of a WHO algorithm with risk assessment for the clinical management of vaginal discharge in Mwanza, Tanzania," Sexually Transmitted Infections, vol. 74, supplement 1, pp. S77-S84, 1998.

[17] M. Chiduo, Z. P. Theilgaard, V. Bakari et al., "Prevalence of sexually transmitted infections among women attending antenatal clinics in Tanga, north eastern Tanzania," International Journal of STD and AIDS, vol. 23, no. 5, pp. 325-329, 2012.

[18] C. Menéndez, X. Castellsagué, M. Renom et al., "Prevalence and risk factors of sexually transmitted infections and cervical neoplasia in women from a rural area of southern Mozambique," Infectious Diseases in Obstetrics and Gynecology, vol. 2010, Article ID 609315, 9 pages, 2010.

[19] S. Govender, G. B. Theron, H. J. Odendaal, and L. J. Chalkley, "Prevalence of genital mycoplasmas, ureaplasmas and chlamydia in pregnancy," Journal of Obstetrics and Gynaecology, vol. 29, no. 8, pp. 698-701, 2009.

[20] M. De Jongh, M. R. Lekalakala, M. Le Roux, and A. A. Hoosen, "Risk of having a sexually transmitted infection in women presenting at a termination of pregnancy clinic in Pretoria, South Africa," Journal of Obstetrics and Gynaecology, vol. 30, no. 5, pp. 480-483, 2010.

[21] G. G. G. Donders, J. Desmyter, D. H. De Wet, and F. A. Van Assche, "The association of gonorrhoea and syphilis with premature birth and low birthweight," Genitourinary Medicine, vol. 69, no. 2, pp. 98-101, 1993.

[22] H. J. van Rensburg and H. J. Odendaal, "The prevalence of potential pathogenic micro-organisms in the endocervix of pregnant women at Tygerberg Hospital," South African Medical Journal, vol. 81, no. 3, pp. 156-157, 1992.

[23] D. Moodley, P. Moodley, M. Sebitloane et al., "High prevalence and incidence of asymptomatic sexually transmitted infections during pregnancy and postdelivery in KwaZulu Natal, South Africa," Sexually Transmitted Diseases, vol. 42, no. 1, pp. 43-47, 2015.

[24] K. Adachi, J. D. Klausner, C. C. Bristow et al., "Chlamydia and gonorrhea in HIV-infected pregnant women and infant HIV transmission," Sexually Transmitted Diseases, vol. 42, no. 10, pp. 554-565, 2015.

[25] M. Romoren, M. Rahman, J. Sundby, and P. Hjortdahl, "Chlamydia and gonorhea in pregnancy: effectiveness of diagnosis and treatment in Botswana," Sexually Transmitted Infections, vol. 80, no. 5, pp. 395-400, 2004.

[26] R. H. Gray, F. Wabwire-Mangen, G. Kigozi et al., "Randomized trial of presumptive sexually transmitted disease therapy during pregnancy in Rakai, Uganda," American Journal of Obstetrics and Gynecology, vol. 185, no. 5, pp. 1209-1217, 2001.

[27] K. Agholor, L. Omo-Aghoja, and F. Okonofua, "Association of anti-Chlamydia antibodies with ectopic pregnancy in Benin city, Nigeria: a case-control study," African Health Sciences, vol. 13, no. 2, pp. 430-440, 2013.

[28] A. Bourgeois, D. Henzel, G. Malonga-Mouelet et al., "Clinical algorithms for the screening of pregnant women for STDs in
Libreville, Gabon: which alternatives?" Sexually Transmitted Infections, vol. 74, no. 1, pp. 35-39, 1998.

[29] R. M. Chico, P. Mayaud, C. Ariti, D. Mabey, C. Ronsmans, and D. Chandramohan, "Prevalence of malaria and sexually transmitted and reproductive tract infections in pregnancy in sub-Saharan Africa: a systematic review," The Journal of the American Medical Association, vol. 307, no. 19, pp. 2079-2086, 2012.

[30] J. Yu, S. Wu, F. Li, and L. Hu, "Vertical transmission of Chlamydia trachomatis in Chongqing China," Current Microbiology, vol. 58, no. 4, pp. 315-320, 2009.

[31] X.-S. Chen, Y.-P. Yin, L.-P. Chen et al., "Sexually transmitted infections among pregnant women attending an antenatal clinic in Fuzhou, China," Sexually Transmitted Diseases, vol. 33, no. 5, pp. 296-301, 2006.

[32] Y. H. Li, Q. L. Wu, Y. M. Zou, W. F. Pan, D. Peng, and X. Y. Liu, "Relationship between the colonization of group B Streptococci, Mycoplasma, and Chlamydia trachomatis infections and spontaneous abortion due to early embryonic death," Acta Academiae Medicinae Sinicae, vol. 32, no. 5, pp. 513-515, 2010.

[33] L. Shen, S. Wu, and G. Liu, "Study on the perinatal infection caused by Chlamydia trachomatis," Zhonghua Fu Chan Ke Za Zhi, vol. 30, no. 12, pp. 714-717, 1995.

[34] S. Wu, L. Shen, and G. Liu, "Study on vertical transmission of Chlamydia trachomatis using PCR and DNA sequencing," Chinese Medical Journal, vol. 112, no. 5, pp. 396-399, 1999.

[35] W. H. Zhang, Y. Y. Wu, and S. R. Fan, "A prospective study of maternal-infant transmission of Chlamydia trachomatis," Chinese Journal of Ophthalmology, vol. 30, no. 5, pp. 357-359, 1994.

[36] O. Amindavaa, S. Kristensen, C. Y. Pak et al., "Sexually transmitted infections among pregnant women attending antenatal clinics in Mongolia: potential impact on the Mongolian HIV epidemic," International Journal of STD \& AIDS, vol. 16, no. 2, pp. 153-157, 2005.

[37] A. Jain, V. L. Nag, M. M. Goel, Chandrawati, and U. C. Chaturvedi, "Adverse foetal outcome in specific IgM positive Chlamydia trachomatis infection in pregnancy," The Indian Journal Of Medical Research, vol. 94, pp. 420-423, 1991.

[38] V. K. Paul, M. Singh, U. Gupta et al., "Chlamydia trachomatis infection among pregnant women: prevalence and prenatal importance," The National Medical Journal of India, vol. 12, no. 1, pp. 11-14, 1999.

[39] S. Rastogi, B. Das, S. Salhan, and A. Mittal, "Effect of treatment for Chlamydia trachomatis during pregnancy," International Journal of Gynecology and Obstetrics, vol. 80, no. 2, pp. 129-137, 2003.

[40] N. K. Vidwan, A. Regi, M. Steinhoff et al., "Low prevalence of Chlamydia trachomatis infection in non-urban pregnant women in Vellore, S. India," PLoS ONE, vol. 7, no. 5, Article ID e34794, 2012.

[41] R. Alexander, E. Mathai, V. Nayyar, M. Mathew, and P. Jasper, "Low prevalence of chlamydial endocervical infection in antenatal South Indian women," Genitourinary Medicine, vol. 69, no. 3, pp. 240-241, 1993.

[42] A. Malik, S. Jain, M. Rizvi, I. Shukla, and S. Hakim, "Chlamydia trachomatis infection in women with secondary infertility," Fertility and Sterility, vol. 91, no. 1, pp. 91-95, 2009.

[43] P. Christian, S. K. Khatry, S. C. LeClerq et al., "Prevalence and risk factors of chlamydia and gonorrhea among rural Nepali women," Sexually Transmitted Infections, vol. 81, no. 3, pp. 254258, 2005. 
[44] M. Rahman, S. B. Chowdhury, N. Akhtar, M. Jahan, M. K. Jahan, and S. Jebunnahar, "Chlamydia trachomatis IgM seropositivity during pregnancy and assessment of its risk factors," Mymensingh Medical Journal, vol. 23, no. 1, pp. 62-68, 2014.

[45] N. U. Mahmud, M. A. Hossain, K. Nahar et al., "Seroprevalence of genital Chlamydia trachomatis infection in women of reproductive age," Mymensingh Medical Journal, vol. 20, no. 2, pp. 187-191, 2011.

[46] R. A. Wangnapi, S. Soso, H. W. Unger et al., "Prevalence and risk factors for Chlamydia trachomatis, Neisseria gonorrhoeae and Trichomonas vaginalis infection in pregnant women in Papua New Guinea," Sexually Transmitted Infections, vol. 91, no. 3, pp. 194-200, 2015.

[47] H. W. Unger, M. Ome-Kaius, R. A. Wangnapi et al., "Sulphadoxine-pyrimethamine plus azithromycin for the prevention of low birthweight in Papua New Guinea: a randomised controlled trial," BMC Medicine, vol. 13, no. 1, article 9, 2015.

[48] S. J. Cliffe, S. Tabrizi, and E. A. Sullivan, "Chlamydia in the pacific region, the silent epidemic," Sexually Transmitted Diseases, vol. 35, no. 9, pp. 801-806, 2008.

[49] P. Chotnopparatpattara, S. Limpongsanurak, and A. Wongprechasawas, "The prevalence of Chlamydia trachomatis infection in pregnant Thai women," Journal of the Medical Association of Thailand, vol. 86, supplement 2, pp. S399-S403, 2003.

[50] P. Chaisilwattana, R. Chuachoowong, W. Siriwasin et al., "Chlamydial and gonococcal cervicitis in HIV-seropositive and HIV-seronegative pregnant women in Bangkok: prevalence, risk factors, and relation to perinatal HIV transmission," Sexually Transmitted Diseases, vol. 24, no. 9, pp. 495-502, 1997.

[51] P. H. Kilmarx, C. M. Black, K. Limpakarnjanarat et al., "Rapid assessment of sexually transmitted diseases in a sentinel population in Thailand: prevalence of chlamydial infection, gonorrhoea, and syphilis among pregnant women-1996," Sexually Transmitted Infections, vol. 74, no. 3, pp. 189-193, 1998.

[52] S. Rastogi, S. Salhan, and A. Mittal, "Detection of Chlamydia trachomatis antigen in spontaneous abortions. Is this organism a primary or secondary indicator of risk?" British Journal of Biomedical Science, vol. 57, no. 2, pp. 126-129, 2000.

[53] Q. Zhu, C. Li, W.-H. Zhao et al., "Risk factors and clinical features of ovarian pregnancy: a case-control study," BMJ Open, vol. 4, no. 12, Article ID e006447, 2014.

[54] O. Khin Nwe, A. Wah, T. Moe, W. Khin Thet, Y. Hta, and M. Win Win, "Case-control study of ectopic pregnancies in Myanmar: infectious etiological factors," The Southeast Asian Journal of Tropical Medicine and Public Health, vol. 42, no. 2, pp. 347-354, 2011.

[55] S. Hornung, B. C. Thuong, J. Gyger et al., "Role of Chlamydia trachomatis and emerging Chlamydia-related bacteria in ectopic pregnancy in Vietnam," Epidemiology and Infection, vol. 143, no. 12, pp. 2635-2638, 2015.

[56] Y. Ville, M. Leruez, E. Glowaczower, J. N. Robertson, and M. E. Ward, "The role of Chlamydia trachomatis and Neisseria gonorrhoeae in the aetiology of ectopic pregnancy in Gabon," British Journal of Obstetrics and Gynaecology, vol. 98, no. 12, pp. 12601266, 1991.

[57] M. L. Cisse, J. C. Moreau, D. Kouedou et al., "Fertility after ectopic pregnancy at the University Hospital in Dakar," Dakar Médical, vol. 47, no. 1, pp. 1-4, 2002.

[58] X. De Muylder, "Ectopic pregnancy in Zimbabwe," International Journal of Gynecology and Obstetrics, vol. 35, no. 1, pp. 55-60, 1991.
[59] G. G. G. Donders, P. Moerman, G. H. De Wet, P. Hooft, and P. Goubau, "The association between Chlamydia cervicitis, chorioamnionitis and neonatal complications," Archives of Gynecology and Obstetrics, vol. 249, no. 2, pp. 79-85, 1991.

[60] K. Adachi, J. D. Klausner, J. Xu et al., "Chlamydia trachomatis and neisseria gonorrhoeae in HIV-infected pregnant women and adverse infant outcomes," The Pediatric Infectious Disease Journal, In press.

[61] P. Datta, M. Laga, F. A. Plummer et al., "Infection and disease after perinatal exposure to Chlamydia trachomatis in Nairobi, Kenya," The Journal of Infectious Diseases, vol. 158, no. 3, pp. 524528, 1988.

[62] P. Khauv, P. Turner, C. Soeng et al., "Ophthalmic infections in children presenting to Angkor Hospital for Children, Siem Reap, Cambodia," BMC Research Notes, vol. 7, article 784, 2014.

[63] S.-X. Wu, J. Yang, and G. Liu, "A clinical study in China of neonatal conjunctivitis caused by Chlamydia trachomatis," Clinical Pediatrics, vol. 42, no. 1, pp. 83-84, 2003.

[64] T. P. P. Yip, W. H. Chan, K. T. Yip et al., "Incidence of neonatal chlamydial conjunctivitis and its association with nasopharyngeal colonisation in a Hong Kong hospital, assessed by polymerase chain reaction," Hong Kong Medical Journal, vol. 13, no. 1, pp. 22-26, 2007.

[65] T. M. Jhon and T. Y. Chang, "Prevalence of Chlamydia trachomatis infection in infants \& children," Zhonghua Minguo xiao er ke yi xue hui za zhi, vol. 30, no. 3, pp. 187-190, 1989.

[66] S. K. Ng, E. Au, and T. Thirumoothy, "Ophthalmia neonatorum-the Middle Road Hospital perspective," Annals of the Academy of Medicine Singapore, vol. 16, no. 4, pp. 645-647, 1987.

[67] A. Sergiwa, B. C. Pratt, E. Eren, T. C. Sunona, and C. A. Hart, "Ophthalmia neonatorum in Bangkok: the significance of Chlamydia trachomatis," Annals of Tropical Paediatrics, vol. 13, no. 3, pp. 233-236, 1993.

[68] N. J. F. Buisman, T. A. Mwemba, G. Garrigue, J. P. Durand, J. S. Stilma, and T. M. van Balen, "Chlamydia ophthalmia neonatorum in Cameroon," Documenta Ophthalmologica, vol. 70, no. 2-3, pp. 257-264, 1988.

[69] E. Frost, F. Yvert, J. Z. Ndong, and B. Ivanoff, "Ophthalmia neonatorum in a semi-rural African community," Transactions of the Royal Society of Tropical Medicine and Hygiene, vol. 81, no. 3, pp. 378-380, 1987.

[70] D. Mabey, P. Hanlon, L. Hanlon, V. Marsh, and T. Forsey, "Chlamydial and gonococcal ophthalmia neonatorum in The Gambia," Annals of Tropical Paediatrics, vol. 7, no. 3, pp. 177-180, 1987.

[71] P. Datta, E. Frost, R. Peeling et al., "Ophthalmia neonatorum in a trachoma endemic area," Sexually Transmitted Diseases, vol. 21, no. 1, pp. 1-4, 1994.

[72] L. Fransen, H. Nsanze, V. Klauss et al., "Ophthalmia neonatorum in Nairobi, Kenya: the roles of Neisseria gonorrhoeae and Chlamydia trachomatis," Journal of Infectious Diseases, vol. 153, no. 5, pp. 862-869, 1986.

[73] Y. F. Ngeow, A. F. Weil, N. S. Khairullah et al., "Young Malaysian children with lower respiratory tract infection 's show low incidence of chlamydial infection," Journal of Paediatrics and Child Health, vol. 33, no. 5, pp. 422-425, 1997.

[74] P. Puthavathana, S. Habanananda, C. Wasi et al., "Incidence of Mycoplasma pneumoniae, Chlamydia trachomatis, and viral infections in pneumonia cases under six months of age, Bangkok, Thailand," The Southeast Asian Journal of Tropical Medicine and Public Health, vol. 25, no. 4, pp. 657-663, 1994. 
[75] T. Ekalaksananan, C. Pientong, B. Kongyingyoes, S. Pairojkul, J. Teeratakulpisarn, and S. Heng, "Etiology of acute lower respiratory tract infection in children at Srinagarind Hospital, Khon Kaen, Thailand," Southeast Asian Journal of Tropical Medicine and Public Health, vol. 32, no. 3, pp. 513-519, 2001.

[76] C. Pientong, T. Ekalaksananan, J. Teeratakulpisarn, S. Tanuwattanachai, B. Kongyingyoes, and C. Limwattananon, "Atypical bacterial pathogen infection in children with acute bronchiolitis in northeast Thailand," Journal of Microbiology, Immunology and Infection, vol. 44, no. 2, pp. 95-100, 2011.

[77] L. Muhe, M. Tilahun, S. Lulseged et al., "Etiology of pneumonia, sepsis and meningitis in infants younger than three months of age in Ethiopia," The Pediatric Infectious Disease Journal, vol. 18, no. 10, pp. S56-S61, 1999.

[78] I. M. Forgie, K. P. O’neill, N. Lloyd-Evans et al., "Etiology of acute lower respiratory tract infections in Gambian children: I. Acute lower respiratory tract infections in infants presenting at the hospital," The Pediatric Infectious Disease Journal, vol. 10, no. 1, pp. 33-41, 1991.

[79] F. N. Were, A. F. Govedi, G. Revathi, and J. S. Wambani, "Chlamydia as a cause of late neonatal pneumonia at Kenyatta National Hospital, Nairobi," East African Medical Journal, vol. 79, no. 9, pp. 476-479, 2002.

[80] H. J. Zar, "Neonatal chlamydial infections: prevention and treatment," Pediatric Drugs, vol. 7, no. 2, pp. 103-110, 2005.

[81] J. Paavonen and W. Eggert-Kruse, "Chlamydia trachomatis: impact on human reproduction," Human Reproduction Update, vol. 5, no. 5, pp. 433-447, 1999.

[82] M. J. Currie and F. J. Bowden, "The importance of chlamydial infections in obstetrics and gynaecology: an update," The Australian \& New Zealand Journal of Obstetrics and Gynaecology, vol. 47, no. 1, pp. 2-8, 2007.

[83] J. A. McGregor, J. I. French, D. Lawellin, and J. K. Todd, "Preterm birth and infection: pathogenic possibilities," American Journal of Reproductive Immunology and Microbiology, vol. 16, no. 3, pp. 123-132, 1988.

[84] D. Baud, G. Goy, S. Vasilevsky et al., "Roles of bovine Waddlia chondrophila and Chlamydia trachomatis in human preterm birth," New Microbes and New Infections, vol. 3, pp. 41-45, 2015.

[85] D. Baud and G. Greub, "Intracellular bacteria and adverse pregnancy outcomes," Clinical Microbiology and Infection, vol. 17, no. 9, pp. 1312-1322, 2011.

[86] D. Baud, L. Regan, and G. Greub, "Emerging role of Chlamydia and Chlamydia-like organisms in adverse pregnancy outcomes," Current Opinion in Infectious Diseases, vol. 21, no. 1, pp. 70-76, 2008.

[87] R. L. Goldenberg, E. M. McClure, Z. A. Bhutta et al., "Stillbirths: the vision for 2020," The Lancet, vol. 377, no. 9779, pp. 1798-1805, 2011.

[88] S. Brown, "Miscarriage and its associations," Seminars in Reproductive Medicine, vol. 26, no. 5, pp. 391-400, 2008.

[89] S. S. Witkin, A. Neuer, P. Giraldo et al., "Chlamydia trachomatis infection, immunity, and pregnancy outcome," Infectious Diseases in Obstetrics and Gynecology, vol. 5, no. 2, pp. 128-132, 1997.

[90] G. Locksmith and P. Duff, "Infection, antibiotics, and preterm delivery," Seminars in Perinatology, vol. 25, no. 5, pp. 295-309, 2001.

[91] K. A. Ault, B. D. Statland, M. M. Smith King, D. I. L. Dozier, M. L. Joachims, and J. Gunter, "Antibodies to the chlamydial 60 kilodalton heat shock protein in women with tubal factor infertility," Infectious Diseases in Obstetrics and Gynecology, vol. 6, no. 4, pp. 163-167, 1998.
[92] I. J. Bakken, "Chlamydia trachomatis and ectopic pregnancy: recent epidemiological findings," Current Opinion in Infectious Diseases, vol. 21, no. 1, pp. 77-82, 2008.

[93] A. J. Stephens, M. Aubuchon, and D. J. Schust, "Antichlamydial antibodies, human fertility, and pregnancy wastage," Infectious Diseases in Obstetrics and Gynecology, vol. 2011, Article ID 525182, 9 pages, 2011.

[94] T. C. Michels and A. Y. Tiu, "Second trimester pregnancy loss," American Family Physician, vol. 76, no. 9, pp. 1341-1346, 2007.

[95] S. Giakoumelou, N. Wheelhouse, K. Cuschieri, G. Entrican, S. E. Howie, and A. W. Horne, "The role of infection in miscarriage," Human Reproduction Update, vol. 22, no. 1, pp. 116-133, 2015.

[96] L. Regan and R. Rai, "Epidemiology and the medical causes of miscarriage," Bailliere's Best Practice and Research in Clinical Obstetrics and Gynaecology, vol. 14, no. 5, pp. 839-854, 2000.

[97] A. García-Enguídanos, M. E. Calle, J. Valero, S. Luna, and V. Domínguez-Rojas, "Risk factors in miscarriage: a review," European Journal of Obstetrics Gynecology and Reproductive Biology, vol. 102, no. 2, pp. 111-119, 2002.

[98] P. Brocklehurst and R. French, "The association between maternal HIV infection and perinatal outcome: a systematic review of the literature and meta-analysis," British Journal of Obstetrics and Gynaecology, vol. 105, no. 8, pp. 836-848, 1998.

[99] K. F. Schulz, W. Cates Jr., and P. R. O’Mara, "Pregnancy loss, infant death, and suffering: legacy of syphilis and gonorrhoea in Africa," Genitourinary Medicine, vol. 63, no. 5, pp. 320-325, 1987.

[100] D. G. Walker and G. J. Walker, "Forgotten but not gone: the continuing scourge of congenital syphilis," The Lancet Infectious Diseases, vol. 2, no. 7, pp. 432-436, 2002.

[101] M. J. P. M. de Attayde Silva, G. L. D. Florêncio, J. R. E. Gabiatti, R. L. do Amaral, J. Eleutério Júnior, and A. K. da Silveira Gonçalves, "Perinatal morbidity and mortality associated with chlamydial infection: a meta-analysis study," Brazilian Journal of Infectious Diseases, vol. 15, no. 6, pp. 533-539, 2011.

[102] J. Sozio and R. B. Ness, "Chlamydial lower genital tract infection and spontaneous abortion," Infectious Diseases in Obstetrics and Gynecology, vol. 6, no. 1, pp. 8-12, 1998.

[103] S. Osser and K. Persson, "Chlamydial antibodies in women who suffer miscarriage," British Journal of Obstetrics and Gynaecology, vol. 103, no. 2, pp. 137-141, 1996.

[104] P. Oakeshott, P. Hay, S. Hay, F. Steinke, E. Rink, and S. Kerry, "Association between bacterial vaginosis or chlamydial infection and miscarriage before 16 weeks' gestation: prospective community based cohort study," British Medical Journal, vol. 325, no. 7376, article 1334, 2002.

[105] D. Baud, G. Goy, K. Jaton et al., "Role of Chlamydia trachomatis in miscarriage," Emerging Infectious Diseases, vol. 17, no. 9, pp. 1630-1635, 2011.

[106] P.-A. Mårdh, "Influence of infection with Chlamydia trachomatis on pregnancy outcome, infant health and life-long sequelae in infected offspring," Best Practice and Research: Clinical Obstetrics and Gynaecology, vol. 16, no. 6, pp. 847-864, 2002.

[107] J. E. Lawn, M. G. Gravett, T. M. Nunes, C. E. Rubens, and C. Stanton, "Global report on preterm birth and stillbirth (1 of 7): definitions, description of the burden and opportunities to improve data," BMC Pregnancy and Childbirth, vol. 10, supplement 1, article S1, 2010.

[108] S. Cousens, H. Blencowe, C. Stanton et al., "National, regional, and worldwide estimates of stillbirth rates in 2009 with trends since 1995: a systematic analysis," The Lancet, vol. 377, no. 9774, pp. 1319-1330, 2011. 
[109] J. E. Lawn, H. Blencowe, R. Pattinson et al., "Stillbirths: where? When? Why? How to make the data count?" The Lancet, vol. 377, no. 9775, pp. 1448-1463, 2011.

[110] R. L. Goldenbrg, E. M. McClure, S. Saleem, and U. M. Reddy, "Infection-related stillbirths," The Lancet, vol. 375, no. 9724, pp. 1482-1490, 2010.

[111] M. M. Slattery and J. J. Morrison, "Preterm delivery," The Lancet, vol. 360, no. 9344, pp. 1489-1497, 2002.

[112] M. Gencay, M. Koskiniemi, P. Ämmälä et al., “Chlamydia trachomatis seropositivity is associated both with stillbirth and preterm delivery," APMIS: Acta Pathologica, Microbiologica, et Immunologica Scandinavica, vol. 108, no. 9, pp. 584-588, 2000.

[113] T. Nyári, M. Woodward, G. Mészáaros, J. Karsai, and L. Kovács, "Chlamydia trachomatis infection and the risk of perinatal mortality in Hungary," Journal of Perinatal Medicine, vol. 29, no. 1, pp. 55-59, 2001.

[114] L. Kovács, E. Nagy, I. Berbik, G. Mészáros, J. Deák, and T. Nyári, "The frequency and the role of Chlamydia trachomatis infection in premature labor," International Journal of Gynecology and Obstetrics, vol. 62, no. 1, pp. 47-54, 1998.

[115] N. Novikova, "Chlamydial and other foetal infections in miscarriage," in Proceedings of the Infections in Gynaecology and Perinatology, Simrishamn, Sweden, 2000.

[116] B. Liu, C. L. Roberts, M. Clarke, L. Jorm, J. Hunt, and J. Ward, "Chlamydia and gonorrhoea infections and the risk of adverse obstetric outcomes: a retrospective cohort study," Sexually Transmitted Infections, vol. 89, no. 8, pp. 672-678, 2013.

[117] P. Rana, I. Kazmi, R. Singh et al., "Ectopic pregnancy: a review," Archives of Gynecology and Obstetrics, vol. 288, no. 4, pp. 747757, 2013.

[118] C. M. Farquhar, "Ectopic pregnancy," The Lancet, vol. 366, no. 9485, pp. 583-591, 2005.

[119] L. L. Marion and G. R. Meeks, "Ectopic pregnancy: history, incidence, epidemiology, and risk factors," Clinical Obstetrics and Gynecology, vol. 55, no. 2, pp. 376-386, 2012.

[120] J. Musa, P. H. Daru, J. T. Mutihir, and I. A. Ujah, "Ectopic pregnancy in Jos Northern Nigeria: prevalence and impact on subsequent fertility," Nigerian Journal of Medicine, vol. 18, no. 1, pp. 35-38, 2009.

[121] T. Pierre-Marie, H. E. Gregory, D. Maxwell, E. M. Robinson, M. Yvette, and F. J. Nelson, "Maternal mortality in Cameroon: a university teaching hospital report," The Pan African Medical Journal, vol. 21, article 16, 2015.

[122] E. M. Der, C. Moyer, R. K. Gyasi et al., "Pregnancy related causes of deaths in Ghana: a 5-year retrospective study," Ghana Medical Journal, vol. 47, no. 4, pp. 158-163, 2013.

[123] P. E. Bailey, E. Keyes, A. C. Moran, K. Singh, L. Chavane, and B. Chilundo, "The triple threat of pregnancy, HIV infection and malaria: reported causes of maternal mortality in two nationwide health facility assessments in Mozambique, 2007 and 2012," BMC Pregnancy and Childbirth, vol. 15, article 293, 2015.

[124] C. E. Grimes, M. L. Billingsley, A. J. Dare et al., "The demographics of patients affected by surgical disease in district hospitals in two sub-Saharan African countries: a retrospective descriptive analysis," SpringerPlus, vol. 4, no. 1, article 750, 2015.

[125] A. K. Rodgers, J. Wang, Y. Zhang et al., "Association of tubal factor infertility with elevated antibodies to Chlamydia trachomatis caseinolytic protease P," American Journal of Obstetrics \& Gynecology, vol. 203, no. 5, pp. 494.e7-494.e14, 2010.

[126] L. Svensson, P.-A. Mardh, M. Ahlgren, and F. Nordenskjold, "Ectopic pregnancy and antibodies to Chlamydia trachomatis," Fertility and Sterility, vol. 44, no. 3, pp. 313-317, 1985.
[127] R. C. Brunham, R. Peeling, I. Maclean, M. L. Kosseim, and M. Paraskevas, "Chlamydia trachomatis-associated ectopic pregnancy: serologic and histologic correlates," The Journal of Infectious Diseases, vol. 165, no. 6, pp. 1076-1081, 1992.

[128] J. Lan, A. J. C. van den Brule, D. J. Hemrika et al., "Chlamydia trachomatis and ectopic pregnancy: retrospective analysis of salpingectomy specimens, endometrial biopsies, and cervical smears," Journal of Clinical Pathology, vol. 48, no. 9, pp. 815-819, 1995.

[129] M. Toth, D. L. Patton, L. A. Campbell et al., "Detection of chlamydial antigenic material in ovarian, prostatic, ectopic pregnancy and semen samples of culture-negative subjects," American Journal of Reproductive Immunology, vol. 43, no. 4, pp. 218-222, 2000.

[130] A. Karaer, I. Mert, S. Cavkaytar, and S. Batioglu, "Serological investigation of the role of selected sexually transmitted infections in the aetiology of ectopic pregnancy," European Journal of Contraception and Reproductive Health Care, vol. 18, no. 1, pp. 68-74, 2013.

[131] M. El-Shourbagy, K. Abd-El-Maeboud, K. M. Diab, A. ElGhannam, L. Nabegh, and S. Ammar, "Genital Chlamydia trachomatis infection in Egyptian women: incidence among different clinical risk groups," The Journal of Obstetrics and Gynaecology Research, vol. 22, no. 5, pp. 467-472, 1996.

[132] G. I. J. G. Rours, R. R. de Krijger, A. Ott et al., "Chlamydia trachomatis and placental inflammation in early preterm delivery," European Journal of Epidemiology, vol. 26, no. 5, pp. 421-428, 2011.

[133] M. C. McCormick, "The contribution of low birth weight to infant mortality and childhood morbidity," The New England Journal of Medicine, vol. 312, no. 2, pp. 82-90, 1985.

[134] L. Liu, S. Oza, D. Hogan et al., "Global, regional, and national causes of child mortality in 2000-13, with projections to inform post-2015 priorities: an updated systematic analysis," The Lancet, vol. 385, no. 9966, pp. 430-440, 2015.

[135] H. Blencowe, S. Cousens, M. Z. Oestergaard et al., "National, regional, and worldwide estimates of preterm birth rates in the year 2010 with time trends since 1990 for selected countries: a systematic analysis and implications," The Lancet, vol. 379, no. 9832, pp. 2162-2172, 2012.

[136] H. H. Chang, J. Larson, H. Blencowe et al., "Preventing preterm births: analysis of trends and potential reductions with interventions in 39 countries with very high human development index," The Lancet, vol. 381, no. 9862, pp. 223-234, 2013.

[137] March of Dimes, "Save the children," in WHO: Born Too Soon: The Global Action Report on Preterm Birth, C. P. Howson, M. V. Kinney, and J. E. Lawn, Eds., World Health Organization, Geneva, Switzerland, 2012.

[138] M. V. Pararas, C. L. Skevaki, and D. A. Kafetzis, "Preterm birth due to maternal infection: causative pathogens and modes of prevention," European Journal of Clinical Microbiology and Infectious Diseases, vol. 25, no. 9, pp. 562-569, 2006.

[139] M. F. Silveira, K. G. Ghanem, E. J. Erbelding et al., "Chlamydia trachomatis infection during pregnancy and the risk of preterm birth: a case-control study," International Journal of STD \& AIDS, vol. 20, no. 7, pp. 465-469, 2009.

[140] A. D. Heggie, G. G. Lumicao, L. A. Stuart, and M. T. Gyves, "Chlamydia trachomatis infection in mothers and infants. A prospective study," The American Journal of Diseases of Children, vol. 135, no. 6, pp. 507-511, 1981. 
[141] J. FitzSimmons, C. Callahan, B. Shanahan, and D. Jungkind, "Chlamydial infections in pregnancy," The Journal of Reproductive Medicine, vol. 31, no. 1, pp. 19-22, 1986.

[142] P. H. Hardy, J. B. Hardy, E. E. Nell, D. A. Graham, M. R. Spence, and R. C. Rosenbaum, "Prevalence of six sexually transmitted disease agents among pregnant inner-city adolescents and pregnancy outcome," The Lancet, vol. 2, no. 8398, pp. 333-337, 1984.

[143] M. T. Waight, M. M. Rahman, P. Soto, and T. Tran, "Sexually transmitted diseases during pregnancy in Louisiana, 20072009: high-risk populations and adverse newborn outcomes," The Journal of the Louisiana State Medical Society, vol. 165, no. 4, pp. 219-226, 2013.

[144] W. W. Andrews, M. A. Klebanoff, E. A. Thom et al., "Midpregnancy genitourinary tract infection with Chlamydia trachomatis: association with subsequent preterm delivery in women with bacterial vaginosis and Trichomonas vaginalis," American Journal of Obstetrics and Gynecology, vol. 194, no. 2, pp. 493500, 2006.

[145] M. G. Gravett, H. P. Nelson, T. DeRouen, C. Critchlow, D. A. Eschenbach, and K. K. Holmes, "Independent associations of bacterial vaginosis and Chlamydia trachomatis infection with adverse pregnancy outcome," The Journal of the American Medical Association, vol. 256, no. 14, pp. 1899-1903, 1986.

[146] D. H. Martin, L. Koutsky, D. A. Eschenbach et al., "Prematurity and perinatal mortality in pregnancies complicated by maternal Chlamydia trachomatis infections," The Journal of the American Medical Association, vol. 247, no. 11, pp. 1585-1588, 1982.

[147] H. R. Harrison, E. R. Alexander, L. Weinstein, M. Lewis, M. Nash, and D. A. Sim, "Cervical Chlamydia trachomatis and mycoplasmal infections in pregnancy. Epidemiology and outcomes," The Journal of the American Medical Association, vol. 250, no. 13, pp. 1721-1727, 1983.

[148] S. M. Berman, H. R. Harrison, W. T. Boyce, W. J. Haffner, M. Lewis, and J. B. Arthur, "Low birth weight, prematurity, and postpartum endometritis. Association with prenatal cervical Mycoplasma hominis and Chlamydia trachomatis infections," The Journal of the American Medical Association, vol. 257, no. 9, pp. 1189-1194, 1987.

[149] R. L. Sweet, D. V. Landers, C. Walker, and J. Schachter, “Chlamydia trachomatis infection and pregnancy outcome," American Journal of Obstetrics and Gynecology, vol. 156, no. 4, pp. 824833, 1987.

[150] L. S. Alger, J. C. Lovchik, J. R. Hebel, L. R. Blackmon, and M. C. Crenshaw, "The association of Chlamydia trachomatis, Neisseria gonorrhoeae, and group B streptococci with preterm rupture of the membranes and pregnancy outcome," American Journal of Obstetrics and Gynecology, vol. 159, no. 2, pp. 397-404, 1988.

[151] J. Martius, M. A. Krohn, S. L. Millier, W. E. Stamm, K. K. Holmes, and D. A. Eschenbach, "Relationships of vaginal Lactobacillus species, cervical Chlamydia trachomatis, and bacterial vaginosis to preterm birth," Obstetrics \& Gynecology, vol. 71, no. 1, pp. 89-95, 1988.

[152] J. A. McGregor, J. I. French, R. Richter et al., "Cervicovaginal microflora and pregnancy outcome: results of a double-blind, placebo-controlled trial of erythromycin treatment," American Journal of Obstetrics and Gynecology, vol. 163, no. 5, part 1, pp. 1580-1591, 1990.

[153] I. Cohen, J.-C. Veille, and B. M. Calkins, "Improved pregnancy outcome following successful treatment of chlamydial infection," The Journal of the American Medical Association, vol. 263, no. 23, pp. 3160-3163, 1990.
[154] G. M. Ryan Jr., T. N. Abdella, S. G. McNeeley, V. S. Baselski, and D. E. Drummond, "Chlamydia trachomatis infection in pregnancy and effect of treatment on outcome," American Journal of Obstetrics and Gynecology, vol. 162, no. 1, pp. 34-39, 1990.

[155] K. Numazaki, T. Fujikawa, and S. Chiba, "Maternal IgM at midtrimester and preterm delivery," The Lancet, vol. 354, no. 9194, p. 2000, 1999.

[156] K. Numazaki, T. Kusaka, S. Chiba et al., "Perinatal complications are associated with seropositivity for Chlamydia trachomatis during pregnancy," Clinical Infectious Diseases, vol. 23, no. 1, pp. 208-209, 1996.

[157] The John Hopkins Study of Cervicitis and Adverse Pregnancy Outcome, "Association of Chlamydia trachomatis and Mycoplasma hominis with intrauterine growth retardation and preterm delivery," American Journal of Epidemiology, vol. 129, no. 6, pp. 1247-1257, 1989.

[158] J. R. Mann, S. McDermott, and T. Gill, "Sexually transmitted infection is associated with increased risk of preterm birth in South Carolina women insured by Medicaid," The Journal of Maternal-Fetal \& Neonatal Medicine, vol. 23, no. 6, pp. 563-568, 2010.

[159] J. Borges-Costa, C. Matos, and F. Pereira, "Sexually transmitted infections in pregnant adolescents: prevalence and association with maternal and foetal morbidity," Journal of the European Academy of Dermatology and Venereology, vol. 26, no. 8, pp. 972-975, 2012.

[160] H. L. Johnson, K. G. Ghanem, J. M. Zenilman, and E. J. Erbelding, "Sexually transmitted infections and adverse pregnancy outcomes among women attending inner city public sexually transmitted diseases clinics," Sexually Transmitted Diseases, vol. 38, no. 3, pp. 167-171, 2011.

[161] E. Burnett, T. L. Loucks, and M. Lindsay, "Perinatal outcomes in HIV positive pregnant women with concomitant sexually transmitted infections," Infectious Diseases in Obstetrics and Gynecology, vol. 2015, Article ID 508482, 5 pages, 2015.

[162] M. M. Blas, F. A. Canchihuaman, I. E. Alva, and S. E. Hawes, "Pregnancy outcomes in women infected with Chlamydia trachomatis: a population-based cohort study in Washington State," Sexually Transmitted Infections, vol. 83, no. 4, pp. 314-318, 2007.

[163] W. W. Andrews, R. L. Goldenberg, B. Mercer et al., "The preterm prediction study: association of second-trimester genitourinary chlamydia infection with subsequent spontaneous preterm birth," American Journal of Obstetrics \& Gynecology, vol. 183, no. 3, pp. 662-668, 2000.

[164] G. I. J. G. Rours, L. Duijts, H. A. Moll et al., "Chlamydia trachomatis infection during pregnancy associated with preterm delivery: a population-based prospective cohort study," European Journal of Epidemiology, vol. 26, no. 6, pp. 493-502, 2011.

[165] K. Adachi, C. Bristow, K. Nielsen-Saines et al., "Chlamydia and Gonorrhea in HIV-infected pregnant women and infant HIV transmission in NICHD HPTN 040," in Proceedings of the Pediatric Academic Societies and Asian Society for Pediatric Research Joint Meeting, Abstract \# 754433, Vancouver, Canada, May 2014.

[166] D. H. Martin, D. A. Eschenbach, M. F. Gotch et al., "Doubleblind placebo-controlled treatment trial of Chlamydia trachomatis endocervical infections in pregnant women," Infectious Diseases in Obstetrics and Gynecology, vol. 5, no. 1, pp. 1017, 1997. 
[167] A. T. Folger, "Maternal Chlamydia trachomatis infections and preterm birth: the impact of early detection and eradication during pregnancy," Maternal and Child Health Journal, vol. 18, no. 8, pp. 1795-1802, 2014.

[168] J. A. McMillan, L. B. Weiner, H. V. Lamberson et al., "Efficacy of maternal screening and therapy in the prevention of chlamydia infection of the newborn," Infection, vol. 13, no. 6, pp. 263-266, 1985.

[169] M. R. Hammerschlag, "Chlamydial and gonococcal infections in infants and children," Clinical Infectious Diseases, vol. 53, supplement 3, pp. S99-S102, 2011.

[170] J. Schachter, M. Grossman, R. L. Sweet, J. Holt, C. Jordan, and E. Bishop, "Prospective study of perinatal transmission of Chlamydia trachomatis," The Journal of the American Medical Association, vol. 255, no. 24, pp. 3374-3377, 1986.

[171] J. Schachter, J. Holt, E. Goodner, M. Grossman, R. Sweet, and J. Mills, "Prospective study of chlamydial infection in neonates," The Lancet, vol. 314, no. 8139, pp. 377-380, 1979.

[172] I. G. I. J. G. Rours, M. R. Hammerschlag, A. Ott et al., "Chlamydia trachomatis as a cause of neonatal conjunctivitis in Dutch infants," Pediatrics, vol. 121, no. 2, pp. e321-e326, 2008.

[173] T. Darville, "Chlamydia trachomatis infections in neonates and young children," Seminars in Pediatric Infectious Diseases, vol. 16, no. 4, pp. 235-244, 2005.

[174] K. A. Workowski and S. Berman, "Sexually transmitted diseases treatment guidelines, 2010," Morbidity and Mortality Weekly Report, vol. 59, no. 12, pp. 1-110, 2010.

[175] M. R. Hammerschlag, C. Cummings, P. M. Roblin, T. H. Williams, and I. Delke, "Efficacy of neonatal ocular prophylaxis for the prevention of chlamydial and gonococcal conjuntivitis," The New England Journal of Medicine, vol. 320, no. 12, pp. 769$772,1989$.

[176] J. Schachter, R. L. Sweet, M. Grossman, D. Landers, M. Robbie, and E. Bishop, "Experience with the routine use of erythromycin for chlamydial infections in pregnancy," The New England Journal of Medicine, vol. 314, no. 5, pp. 276-279, 1986.

[177] H. R. Harrison, L. M. Taussig, and V. A. Fulginiti, "Chlamydia trachomatis and chronic respiratory disease in childhood," Pediatric Infectious Disease, vol. 1, no. 1, pp. 29-33, 1982.

[178] W. C. Webley, Y. Tilahun, K. Lay et al., "Occurrence of Chlamydia trachomatis and Chlamydia pneumoniae in paediatric respiratory infections," The European Respiratory Journal, vol. 33, no. 2, pp. 360-367, 2009.

[179] G. I. J. G. Rours, M. R. Hammerschlag, G. J. J. Van Doornum et al., "Chlamydia trachomatis respiratory infection in Dutch infants," Archives of Disease in Childhood, vol. 94, no. 9, pp. 705707, 2009

[180] M. Gencay, M. Koskiniemi, P. Saikku et al., "Chlamydia trachomatis seropositivity during pregnancy is associated with perinatal complications," Clinical Infectious Diseases, vol. 21, no. 2, pp. 424-426, 1995.

[181] K. S. Panaretto, H. M. Lee, M. R. Mitchell et al., "Prevalence of sexually transmitted infections in pregnant urban Aboriginal and Torres Strait Islander women in northern Australia," The Australian \& New Zealand Journal of Obstetrics \& Gynaecology, vol. 46, no. 3, pp. 217-224, 2006.

[182] F. Wabwire-Mangen, R. H. Gray, F. A. Mmiro et al., "Placental membrane inflammation and risks of maternal-to-child transmission of HIV-1 in Uganda," Journal of Acquired Immune Deficiency Syndromes and Human Retrovirology, vol. 22, no. 4, pp. 379-385, 1999.
[183] T. E. Taha, E. R. Brown, I. F. Hoffman et al., "A phase III clinical trial of antibiotics to reduce chorioamnionitis-related perinatal HIV-1 transmission," AIDS, vol. 20, no. 9, pp. 1313-1321, 2006.

[184] R. L. Goldenberg, V. Mudenda, J. S. Read et al., "HPTN 024 study: histologic chorioamnionitis, antibiotics and adverse infant outcomes in a predominantly HIV-1-infected African population," American Journal of Obstetrics and Gynecology, vol. 195, no. 4, pp. 1065-1074, 2006.

[185] F. Mwanyumba, P. Galliard, I. Inion et al., "Placental inflammation and perinatal transmission of HIV-1," Journal of Acquired Immune Deficiency Syndromes, vol. 29, no. 3, pp. 262-269, 2002.

[186] B. H. Chi, V. Mudenda, J. Levy, M. Sinkala, R. L. Goldenberg, and J. S. A. Stringer, "Acute and chronic chorioamnionitis and the risk of perinatal human immunodeficiency virus-1 transmission," American Journal of Obstetrics \& Gynecology, vol. 194, no. 1, pp. 174-181, 2006.

[187] M. Alary, J. R. Joly, J.-M. Moutquin et al., "Randomised comparison of amoxycillin and erythromycin in treatment of genital chlamydial infection in pregnancy," The Lancet, vol. 344, no. 8935, pp. 1461-1465, 1994.

[188] W. R. Crombleholme, J. Schachter, M. Grossman, D. V. Landers, and R. L. Sweet, "Amoxicillin therapy for Chlamydia trachomatis in pregnancy," Obstetrics and Gynecology, vol. 75, no. 5, pp. 752756, 1990.

[189] C. Black-Payne, M. M. Ahrabi, J. A. Bocchini Jr., C. R. Ridenour, and R. M. Brouillette, "Treatment of Chlamydia trachomatis identified with Chlamydiazyme during pregnancy. Impact on perinatal complications and infants," The Journal of Reproductive Medicine, vol. 35, no. 4, pp. 362-367, 1990.

[190] T. A. Bell, I. K. Sandstorm, D. A. Eschenbach et al., Treatment of Chlamydia trachomatis in Pregnancy with Amoxicillin, Elsevier Biomedical Press, 1982.

[191] D. C. W. Mabey, V. Hu, R. L. Bailey, M. J. Burton, and M. J. Holland, "Towards a safe and effective chlamydial vaccine: lessons from the eye," Vaccine, vol. 32, no. 14, pp. 1572-1578, 2014.

[192] R. C. Brunham and R. Rappuoli, "Chlamydia trachomatis control requires a vaccine," Vaccine, vol. 31, no. 15, pp. 1892-1897, 2013.

[193] K. Schautteet, E. De Clercq, and D. Vanrompay, "Chlamydia trachomatis vaccine research through the years," Infectious Diseases in Obstetrics and Gynecology, vol. 2011, Article ID 963513, 9 pages, 2011.

[194] S. Vasilevsky, M. Stojanov, G. Greub, and D. Baud, "Chlamydial polymorphic membrane proteins: regulation, function and potential vaccine candidates," Virulence, vol. 7, no. 1, pp. 11-22, 2016.

[195] J. Rey-Ladino, A. G. P. Ross, and A. W. Cripps, "Immunity, immunopathology, and human vaccine development against sexually transmitted Chlamydia trachomatis," Human Vaccines and Immunotherapeutics, vol. 10, no. 9, pp. 2664-2673, 2014.

[196] S. Vasilevsky, G. Greub, D. Nardelli-Haefliger, and D. Baud, "Genital Chlamydia trachomatis: understanding the roles of innate and adaptive immunity in vaccine research," Clinical Microbiology Reviews, vol. 27, no. 2, pp. 346-370, 2014.

[197] K. A. Workowski and G. A. Bolan, "Sexually transmitted diseases treatment guidelines, 2015," Morbidity and Mortality Weekly Report, vol. 64, no. 3, pp. 1-137, 2015.

[198] Public Health Agency of Canada, Report on Sexually Transmitted Infections in Canada: 2010, Centre for Communicable Diseases and Infection Control, Infectious Disease Prevention and Control Branch, Public Health Agency of Canada, Ottawa, Canada, 2012. 
[199] D. S. LaMontagne, K. A. Fenton, S. Randall, S. Anderson, and P. Carter, "Establishing the National Chlamydia Screening Programme in England: results from the first full year of screening," Sexually Transmitted Infections, vol. 80, no. 5, pp. 335-341, 2004.

[200] T. M. Weissenbacher, M. S. Kupka, F. Kainer, K. Friese, and I. Mylonas, "Screening for Chlamydia trachomatis in pregnancy: a retrospective analysis in a German urban area," Archives of Gynecology and Obstetrics, vol. 283, no. 6, pp. 1343-1347, 2011.

[201] N. Low and the Screening for Chlamydia Review in Europe Project Team, Publication of Report on Chlamydia Control Activities in Europe, vol. 13, European Centre for Disease Prevention and Control, Stockholm, Sweden, 2008.

[202] D. Meyers, T. Wolff, K. Gregory et al., "USPSTF recommendations for STI screening," American Family Physician, vol. 77, no. 6, pp. 819-824, 2008.

[203] Excellence National Institute for Health and Clinical Excellence, Antenatal Care, 2008.

[204] M. Romoren, J. Sundby, M. Velauthapillai, M. Rahman, E. Klouman, and P. Hjortdahl, "Chlamydia and gonorrhoea in pregnant Botswana women: time to discard the syndromic approach?” BMC Infectious Diseases, vol. 7, article 27, 2007.

[205] V. M. Pinto, C. L. Szwarcwald, C. Baroni, L. L. Stringari, L. A. Inocêncio, and A. E. Miranda, "Chlamydia trachomatis prevalence and risk behaviors in parturient women aged 15 to 24 in Brazil," Sexually Transmitted Diseases, vol. 38, no. 10, pp. 957961, 2011.

[206] L. Gallo Vaulet, C. Entrocassi, A. I. Corominas, and M. Rodríguez Fermepin, "Distribution study of Chlamydia trachomatis genotypes in symptomatic patients in Buenos Aires, Argentina: association between genotype E and neonatal conjunctivitis," BMC Research Notes, vol. 3, article 34, 2010.

[207] D. Shan, J. Wang, S. Duan et al., "A study on the health economic evaluations of prevention of mother-to-child HIV transmission in Dehong prefecture, Yunnan province, China from 2004 to 2013," Chinese Journal of Preventive Medicine, vol. 49, no. 6, pp. 490-495, 2015.

[208] F.-C. Hong, Y.-Z. Yang, X.-L. Liu et al., "Reduction in motherto-child transmission of syphilis for 10 years in Shenzhen, China," Sexually Transmitted Diseases, vol. 41, no. 3, pp. 188-193, 2014.

[209] L.-G. Yang, J. D. Tucker, F.-Y. Liu et al., "Syphilis screening among 27,150 pregnant women in South Chinese rural areas using point-of-care tests," PLoS ONE, vol. 8, no. 8, Article ID e72149, 2013.

[210] R. W. Peeling, D. Mabey, A. Herring, and E. W. Hook III, "Why do we need quality-assured diagnostic tests for sexually transmitted infections?" Nature Reviews Microbiology, vol. 4, supplement 12, pp. S7-S19, 2006.

[211] Centers for Disease Control and Prevention, "Recommendations for the laboratory-based detection of Chlamydia trachomatis and Neisseria gonorrhoeae-2014," MMWR Recommendations and Reports/Centers for Disease Control, vol. 63, no. 2, pp. 1-19, 2014.

[212] World Health Organization, Laboratory Diagnosis of Sexually Transmitted Infections, Including Human Immunodeficiency Virus, World Health Organization, Geneva, Switzerland, 2013.

[213] C. Gaydos and J. Hardick, "Point of care diagnostics for sexually transmitted infections: perspectives and advances," Expert Review of Anti-Infective Therapy, vol. 12, no. 6, pp. 657-672, 2014.

[214] C.-E. C. Michel, F. G. Saison, H. Joshi, L. M. Mahilum-Tapay, and H. H. Lee, "Pitfalls of internet-accessible diagnostic tests: inadequate performance of a CE-marked Chlamydia test for home use," Sexually Transmitted Infections, vol. 85, no. 3, pp. 187-189, 2009.

[215] Y.-P. Yin, R. W. Peeling, X.-S. Chen et al., "Clinic-based evaluation of Clearview Chlamydia MF for detection of Chlamydia trachomatis in vaginal and cervical specimens from women at high risk in China," Sexually Transmitted Infections, vol. 82, supplement 5, pp. v33-v37, 2006.

[216] S. H. Vermund, "Screening for sexually transmitted infections in antenatal care is especially important among HIV-infected women," Sexually Transmitted Diseases, vol. 42, no. 10, pp. 566568, 2015.

[217] D. Potter, R. L. Goldenberg, A. Chao et al., "Do targeted HIV programs improve overall care for pregnant women? Antenatal syphilis management in Zambia before and after implementation of prevention of mother-to-child HIV transmission programs," Journal of Acquired Immune Deficiency Syndromes, vol. 47, no. 1, pp. 79-85, 2008.

[218] A.-L. Wang, Y.-P. Qiao, L.-H. Wang et al., "Integrated prevention of mother-to-child transmission for human immunodeficiency virus, syphilis and hepatitis B virus in China," Bulletin of the World Health Organization, vol. 93, no. 1, pp. 52-56, 2015.

[219] A. Jain and C. A. Ison, "Chlamydia point-of-care testing: where are we now?" Sexually Transmitted Infections, vol. 89, no. 2, pp. 88-89, 2013.

[220] W. Huang, C. A. Gaydos, M. R. Barnes, M. Jett-Goheen, and D. R. Blake, "Comparative effectiveness of a rapid point-of-care test for detection of Chlamydia trachomatis among women in a clinical setting," Sexually Transmitted Infections, vol. 89, no. 2, pp. 108-114, 2013.

[221] C. A. Gaydos, P. A. Rizzo-Price, P. Balakrishnan et al., "Impact of international laboratory partnerships on the performance of $\mathrm{HIV} /$ sexually transmitted infection testing in five resourceconstrained countries," International Journal of STD \& AIDS, vol. 22, no. 11, pp. 645-652, 2011. 


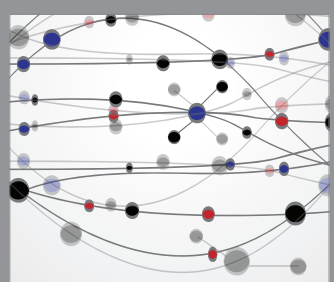

The Scientific World Journal
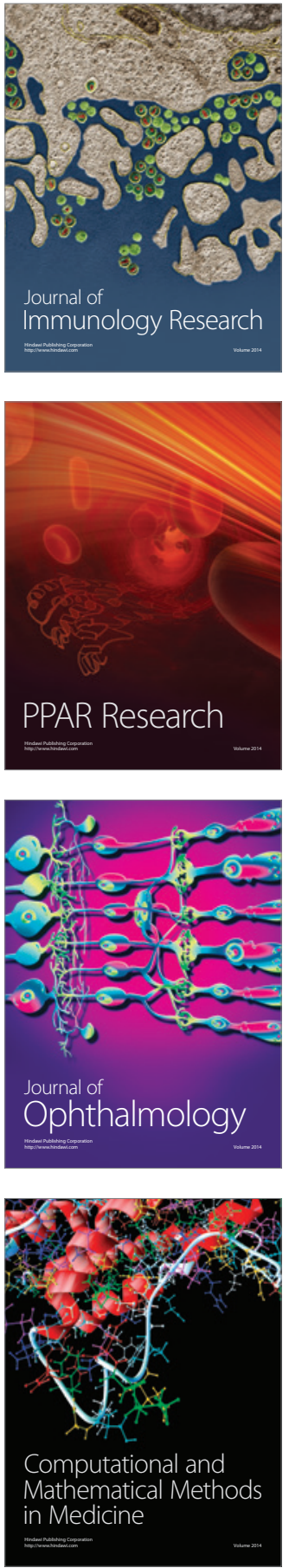

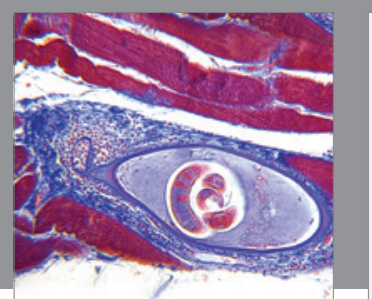

Gastroenterology Research and Practice

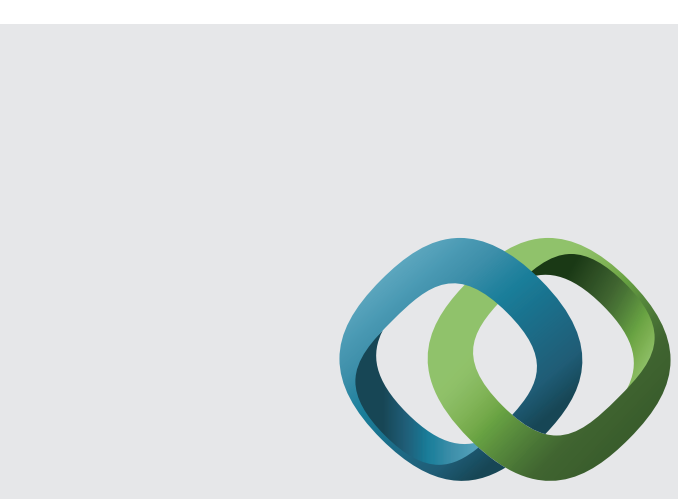

\section{Hindawi}

Submit your manuscripts at

http://www.hindawi.com
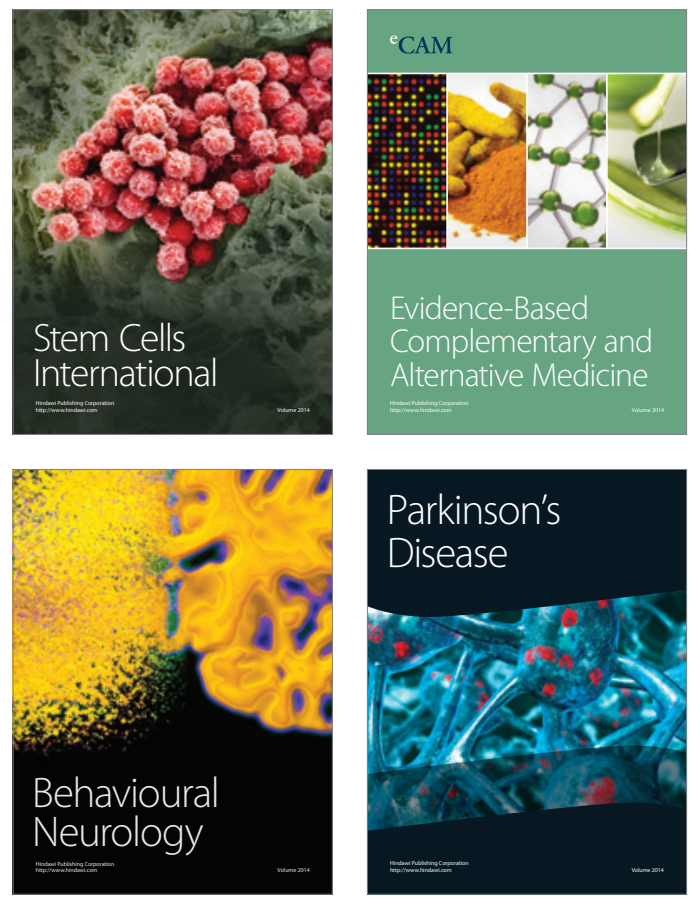
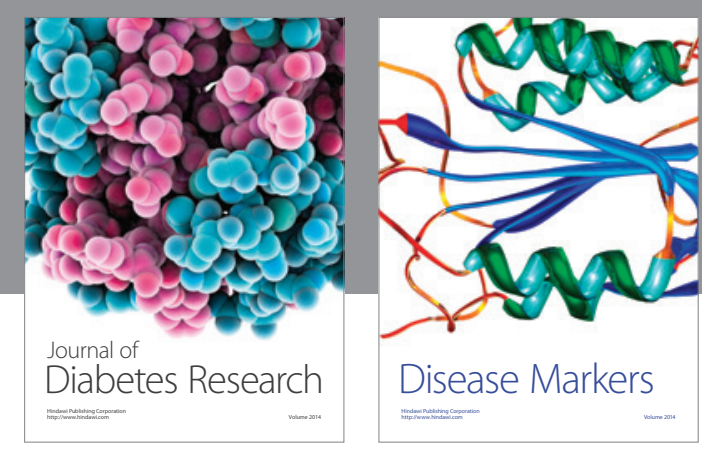

Disease Markers
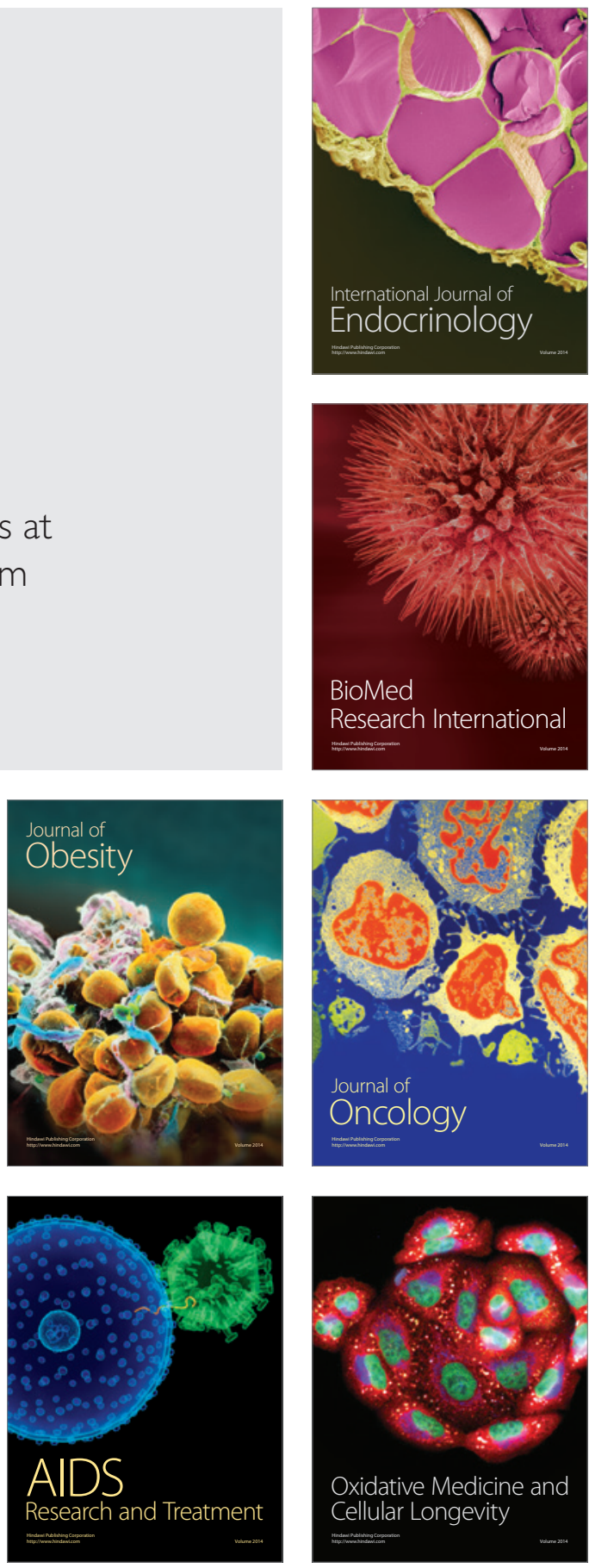